Document downloaded from:

http://hdl.handle.net/10251/105358

This paper must be cited as:

Gómez-Martínez, F.; Alonso Durá, A.; De Luca, F.; Verderame, GM. (2016). Ductility of wide-beam RC frames as lateral resisting system. Bulletin of Earthquake Engineering. 14(6):1545-1569. doi:10.1007/s10518-016-9891-x

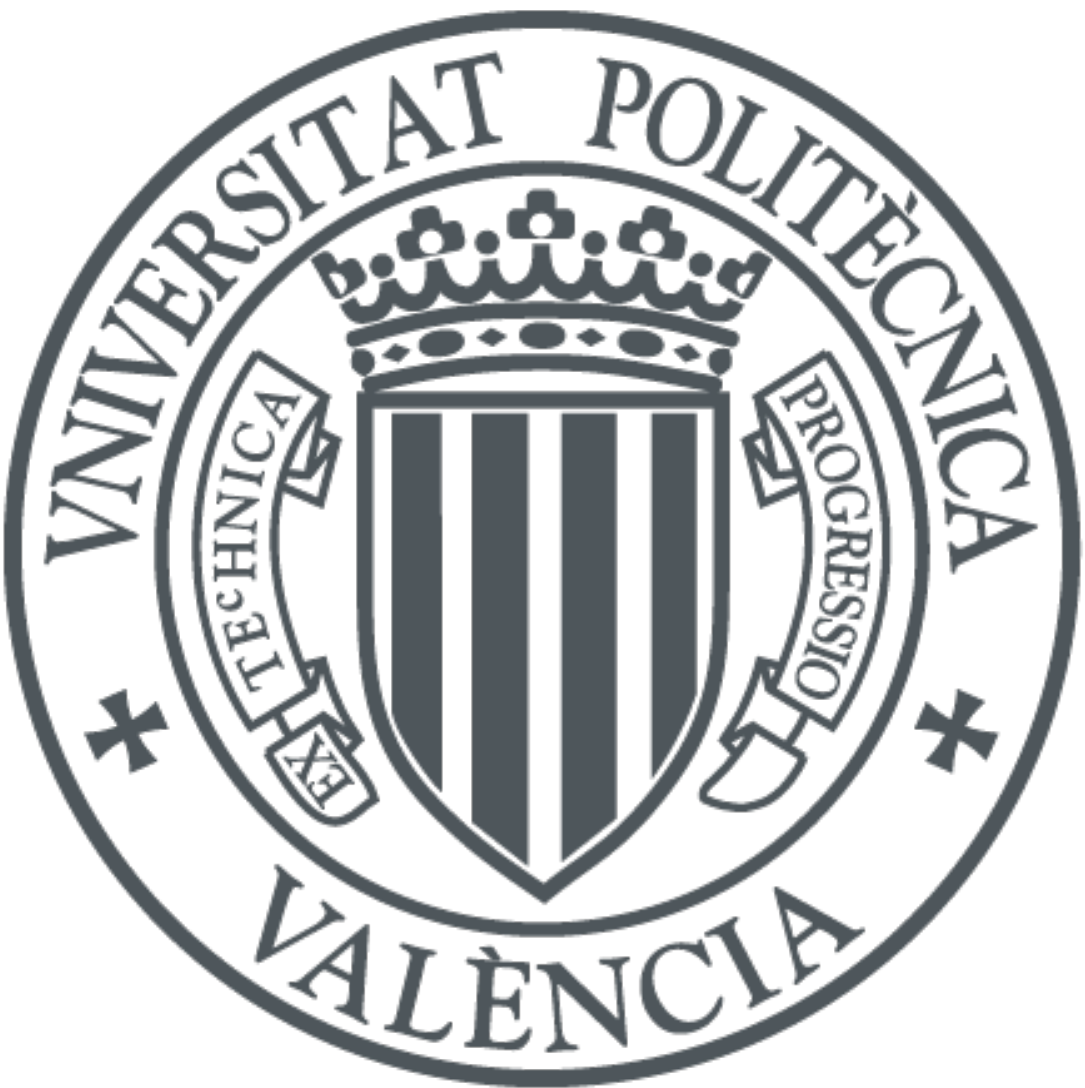

The final publication is available at

http://doi.org/10.1007/s10518-016-9891-x

Copyright Springer-Verlag

Additional Information 


\title{
DUCTILITY OF WIDE-BEAM RC FRAMES AS LATERAL RESISTING SYSTEM
}

\author{
Fernando Gómez-Martínez ${ }^{* 1,2}$, Adolfo Alonso-Durá2, \\ Flavia De Luca ${ }^{3}$, Gerardo M. Verderame ${ }^{1}$ \\ ${ }^{1}$ Department of Structures for Engineering and Architecture, DIST, University of Naples Federico II, \\ Via Claudio, 21, 80125 Naples, Italy \\ ${ }^{2}$ Department of Mechanics of the Continuum Media and Theory of Structures, Polytechnic University of \\ Valencia, Camino de Vera, s/n, 46022 Valencia, Spain \\ ${ }^{3}$ Department of Civil Engineering, University of Bristol, Queen's Building University Walk, BS8 1TR, \\ Bristol, UK
}

\begin{abstract}
Some Mediterranean seismic codes consider wide-beam reinforced concrete moment resisting frames (WBF) as horizontal load carrying systems that cannot guarantee high ductility performances. Conversely, Eurocode 8 allows High Ductility Class (DCH) design for such structural systems. Code prescriptions related to WBF are systematically investigated. In particular, lesson learnt for previous earthquakes, historical reasons, and experimental and numerical studies underpinning specific prescriptions on wide beams in worldwide seismic codes are discussed. Local and global ductility of WBF are then analytically investigated through (i) a parametric study on chord rotations of wide beams with respect to that of deep beams, and (ii) a spectral-based comparison with conventional reinforced concrete moment resisting frames (i.e., with deep beams). Results show that the set of prescriptions given by each modern seismic code provides sufficient ductility to WBF designed in DCH. In fact, global capacity of WBF relies more on the lateral stiffness of the frames and on the overstrength of columns rather than on the local ductility of wide beams, which is systematically lower with respect to that of deep beams.
\end{abstract}

KEYWORDS: Wide beams, deep beams, seismic codes, effective width, behaviour factor, chord rotation, ductility, effective period

\section{INTRODUCTION}

In Mediterranean countries, wide-beam reinforced concrete moment resisting frames (WBF) are a common structural solution for both code conforming and non-conforming ("substandard”) buildings in low-to-moderate seismic prone areas (Arslan and Kormaz, 2007; Vielma et al., 2010; Benavent-Climent and Zahran, 2010; Inel et al., 2013; De Luca et al., 2014; López-

\footnotetext{
* Corresponding author: fergomar@mes.upv.es
} 
Almansa et al., 2013; Domínguez et al., 2014, 2016). On the other hand, such widespread employment of wide beams (WB) instead of conventional deep beams (DB) in seismic regions is more justified by architectural requirements rather than by a broad understanding of their structural behaviour - sometimes considered as intermediate between a common frame and flatslab system (Benavent-Climent, 2007). The employment of WBF can be interpreted as a convenient adaptation of gravity-load systems for low-seismic hazard areas. Moreover, the flat bottom surface is flexible from an architectural point of view and it decreases construction costs by savings in the formwork (Donmez, 2013).

Given the multiple uncertainties concerning WBF performances, traditionally, seismic codes have been quite cautious in allowing their use with the same design rules of deep-beam frames (DBF). Typical restrictions for WBF are the imposition of reduced design behaviour factors $(q)$, or even to prevent their use in seismic high-hazard areas. Nevertheless, different experimental and analytical studies regarding seismic performances of wide beam-column connections concluded that, if some basic design rules are taken into account, local performance of WBF connections may be as satisfactory as that of DBF (see section 3). Therefore, more recently, current international benchmark seismic codes, such as European Eurocode 8 part 1 EC8- (CEN, 2004), American ACI 318-08 (ACI, 2008) or New Zealander NZS 3101 (NZS, 2006) do not present any restriction for WBF as high ductility systems. However, some national seismic codes in the Mediterranean area still do so, such as Spanish NCSE-02 (CDSC, 2002), Italian NTC (CS.LL.PP, 2009) or Greek EAK 2000 (MEPP, 2000a) (see section 2).

The discussion herein is aimed at providing a suitable mechanical interpretation of the restrictions on WBF in Mediterranean codes (section 2) through the examination of experimental background. Local and global ductility of WBF are then analytically investigated through (i) a parametric study on curvatures and chord rotations of wide beams with respect to that of deep beams (section 3), and (ii) a spectral-based comparison with conventional DBF (section 4). Finally, the analytical results of this study are summarized and conclusions on high ductility WBF are drawn (section 5).

\section{CODE DESIGN PROVISIONS FOR WIDE BEAMS}

EC8 have been influencing European National codes for the last ten years, and often European countries have adopted it through the release of National Annexes. However, some 
differences can still be found with respect to design rules on WBF in codes of some Mediterranean countries such as Italy -NTC—, Spain -NCSE-02—, Turkey -TSI (MPWS, 2007)—, and Greece -EAK 2000—.

Some of the following typical restrictions on WBF can be found in Mediterranean codes:

- $\quad$ it cannot be the only lateral resisting system in the building;

- $\quad$ it cannot be designed as High Ductility Class (DCH) system;

- $\quad$ wide beam-column connections must satisfy geometric and mechanical limitations.

It is not clear whether the above restrictions respond to specific mechanical models based on analytical or experimental results or they are just conservative legacies from old construction practice. They can be either based on the behaviour observed in flat-slab frames (NZS, 2006; Fardis, 2009), which show scarce local and global ductility; i.e., due to punching shear failure or to the difficulty to ensure capacity design of columns, respectively.

In the following, it is carried out a general review of the limitations provided by Mediterranean codes on WBF compared to other international codes: EC8; ACI 318-08 complemented with ACI 352R-02 (ACI-ASCE, 2002) and ASCE/SEI 7-10 (ASCE, 2010); and NZS 3101 (NZS, 2006) complemented with NZS 1170.5 (NZS, 2004). All the specific prescriptions are summarised in Table 1.

\subsection{Code provisions for flat-slab frames}

Before going through a review of WBF code provisions, it is necessary to have an overview of what codes provide for flat-slab structures. In fact, most of the rules on WBF often look like an adaptation of flat-slab restrictions. Past versions of ACI 318 (ACI, 1989) prescribed to avoid flat-slab structures unless they were coupled with shear walls as lateral load carrying system. Current codes still provide severe restrictions to flat-slab employment with respect to three main aspects: (i) site-hazard, (ii) deformability, and (iii) ductility.

Regarding site-hazard, only EC8 and TSI recommend not to use flat slab as "primary seismic” elements when the design peak ground acceleration (PGA) is higher than 0.08g and $0.20 \mathrm{~g}$, respectively. In particular, TSI limit applies to flat slab systems without walls, considered as systems of nominal ductility level (see Table 1).

Regarding deformability, modern codes set acceptable values for interstorey drift ratio (IDR) -aimed at designing to Damage Limitation Limit State (DLS) - regardless of the structural system considered, but still some codes, such as NZS 3101, provide more restrictive 
IDR limitations for flat-slab structures (see Table 1). Other codes present qualitative limitations for the deformed shape. In Greek EAK 2000, typical frame internal forces (i.e., opposite bending moments at the two ends of members) are required for columns in flat-slab structures, to be achieved through a sufficient stiffness of beams; otherwise, the lateral load carrying system has to be shear walls. Moreover, other codes limit the overall height of the building when flat slab is the only resisting system, e.g., 13m for TSI and 10m or three storeys for the Iranian seismic code (BHRC, 2004). Regarding ductility, most codes do not allow considering flat-slab systems as DCH system, and consequently they cap the maximum $q$ (see Table 1 ).

On the other hand, codes do not explicitly clarify if behaviour and design of one-way slabs (which is very often used in conjunction with WB) can be assimilated to flat slabs rather than to WB; neither is it explicitly clarified whether the same effective widths are required for reinforcement arrangements near the columns. NCSE-02 is the only code establishing explicitly that one-way joist slabs, waffle slabs, and flat solid slabs shall be treated similarly to beams concerning all the prescriptions referred to geometry and reinforcement arrangements.

\subsection{Code provisions for wide-beam frames}

Similarly to flat-slab structures, both American ACI 352R-91 (ACI-ASCE, 1991) and Spanish NCSR-94 (CDSC, 1994) standards, in 1990s', limited the employment of WBF in seismic regions: ACI 352R-91 recommended not using them, while NCSR-94 allowed the employment up to $0.16 \mathrm{~g}$.

In recent years, almost all the codes have removed any limitation to the use of WBF as the only lateral resisting system. However, some current codes still make it almost impossible: EAK 2000 imposes the same rules than for flat-slab frames regarding deformed shape, while NZS 3101 requires so large values of $h_{b} / \phi_{c}$ (being $h_{b}$ the beam depth and $\phi_{c}$ the maximum diameter of column bars) that the use of WB becomes not viable ( $h_{b}$ usually larger than $40 \mathrm{~cm}$ ).

Regarding limitations for the design ductility class, current Spanish and Italian national codes prevent WBF from being a high ductility system. Spanish NCSE-02 applies 50\% reduction of $q$ downgrading WBF to Low Ductility Class (DCL), so that $q$ ends to 2.0. Italian NTC applies a 33\% reduction, so that $q$ becomes 3.90, corresponding to Medium Ductility Class (DCM). The Italian restriction is more surprising than that of Spanish code; in fact, NTC is a local arrangement of EC8, while NCSE-02 differs in many basic aspects with respect to EC8 (GómezMartínez et al., 2015a,b). It is worth noting that, generally, international standards (such as EC8) 
do not relate ductility to structural typologies but more to design requirements, progressively relaxed from high to medium and low ductility classes (e.g., minimum dimensions, minimum reinforcements, local ductility, axial load limitation, capacity design rules...). However, the limitations for DCL provided by NCSE-02 are more severe than those provided by other codes.

Nevertheless, most of seismic standards, rather than limiting explicitly the employment of WBF, establish geometrical restrictions to wide beam-column (WB-C) connections as condition for the application of typical design procedures (Table 1 and Fig. 1). These restrictions are meant to ensure the stress transfer within WB-C connections; otherwise, full capacity of beams cannot be exploited.

The effective width of a beam is the fraction of the total width which satisfies flexural equilibrium of forces when framing a narrower column within a connection. Current codes provide maximum values to beam width $\left(b_{w}\right)$ in order to make it agree with the effective width. Furthermore, some limits on the amount of top reinforcement to be placed within the width of the beam or in the upper slab flange, as well as some definitions of effective width for other mechanisms (shear equilibrium of beam and joint panel), underpin the same basic principles. Other geometrical restrictions are oriented to ensure adequate bond behaviour of the longitudinal reinforcement; this is the case of lower limits to members' depths.

Code prescriptions regarding $b_{w}$ rely on different approaches, as shown in detail in Table 1 , where maximum values of $w$ (the "outer" part of $b_{w}$ at each side of the column) are shown aimed at homogenisation with other provisions. Most codes forbid to design $b_{w}$ larger than a specific limit, while others permit any $b_{w}$ as long as the reinforcement required to satisfy flexural demand is placed within effective width (as in NZS 3101, NCSE-02 and somehow EC8). The above limitations are usually not mandatory for DCL except for some codes (e.g. NCSE-02 and NTC). The evaluation of the effective width is made on the basis of other dimensions; according to NZS 3101, ACI 318-08 and Greek EKOS 2000 (MEPP, 2000b), it depends on column depth $\left(h_{c}\right)$, while the rest of codes relate effective width to $h_{b}$. EAK 2000, TSI, NTC, EC8 and ACI 31808 limit $b_{w}$ also on the basis of column width $\left(b_{c}\right)$. Furthermore, NZS 3101, NCSE-02 and ACI 318-08 provide explicit rules for the case of edge beams. The most severe restriction is given by NCSE-02: all the upper and bottom reinforcement must be placed within the column core unless transverse beams are present. Conversely, the most relaxed rule seems to be in EC8: placing the reinforcement within the effective width is only an option in order "to take advantage of the 
favourable effect of column compression on the bond of horizontal bars passing through the joint”; however it is extensively considered as compulsory in the practice (Benavent-Climent et al., 2010; Fadwa et al., 2014)

Other prescriptions ask for a specific amount of upper WB reinforcement to be placed within the column core (i.e. passing through $b_{c}$ ). This kind of prescriptions differs significantly among different codes (see Table 1). It is worth noting that NZS 3101 requirement is not referred to the column core but to the effective width, and the remaining $10 \%$ of reinforcement can be placed within the upper slab effective width.

The eccentricity between the axis of the beam and that of the column is often limited. In the case of edge beams (see Table 1), this requirement indirectly limits $b_{w}$, being in most cases consistent with the effective width limitation. NTC is the only code that allows higher eccentricities if proper reinforcement is placed in the perpendicular direction.

Codes in which $b_{w}$ limitation is referred to the web or to the gross section might assume implicitly $b_{w}$ to be the effective width for both flexure and shear. Conversely, NCSE-02 considers that shear is able to be equilibrated at joint face only within the column core, providing a conceptual difference from flexure and shear effective width.

Some codes also establish an explicit minimum value for beam depth $h_{b} \geq 30 \mathrm{~cm}$, as Iranian code and TSI, which also relates minimum depth to the thickness of the upper slab (see Table 1).

Code restrictions regarding contribution of the upper slab to the flexural performance can be divided in two groups: restrictions depending only on the local geometry of the connections, and those depending also on the beam span. Some codes, for sake of conservativeness, propose different magnitudes depending on the purpose of the evaluation: lower values for flexural design of the beam, and higher values for assessing maximum flexural capacity of beams for capacity design of columns and joints. Such codes always refer to the effectiveness of tensioned reinforcement, and there is no mention to the compressive behaviour. It is not clear how to account for the contribution of the upper slab in the case of WBF. In fact, when no transverse beam is present, WB's web or longitudinal reinforcement can be wider than the column, but none of the upper reinforcement placed outside the column core may be effective according to the upper slab tensioned flange restriction. ACI 352R-02 is the only code requiring torsional evaluation of the transverse beam subjected to the action induced by the upper slab bars within the effective slab width. 
Regarding effective shear width of WB-C joint, NZS 3101, NTC and EC8 establish that it may be higher than the strict volume contained within the intersection of members (i.e. larger than the joint panel).

Finally, NZS 3101, NTC, EC8 and ACI 318-08 provide upper limits to the diameters of longitudinal bars of beams with respect to $h_{c}$ aimed at proper bond behaviour within connections. These limitations make it difficult to reduce significantly column sections at upper storeys. 
Table 1: Prescriptions regarding flat-slab and wide-beam frames systems according to different codes

\begin{tabular}{|c|c|c|c|c|c|c|c|c|c|c|c|c|c|c|c|c|}
\hline \multirow{3}{*}{\multicolumn{2}{|c|}{$\begin{array}{c}\text { CODE } \\
\text { (seismic, RC, connections) }\end{array}$}} & \multirow{3}{*}{$\begin{array}{l}\text { Max. } \\
\text { IDR }^{(1)} \\
{[\%]}\end{array}$} & \multicolumn{4}{|c|}{ BEAMLESS TWO-WAY FLAT SLAB } & \multicolumn{10}{|c|}{ WIDE BEAMS } \\
\hline & & & \multirow[b]{2}{*}{$\begin{array}{l}\text { Max. } a_{g} \\
{[\mathrm{~g}]}\end{array}$} & \multirow{2}{*}{$\begin{array}{c}\text { Deforma } \\
\text {-bility } \\
\text { restric- } \\
\text { tions }\end{array}$} & \multirow{2}{*}{\multicolumn{2}{|c|}{$\begin{array}{l}\text { Max. duct. } \\
\text { class ( } q \\
\text { reduction } \\
\text { from DCH) } \\
\end{array}$}} & \multirow[b]{2}{*}{$\begin{array}{l}\text { Min. } h_{b} \\
{[\mathrm{~cm}]}\end{array}$} & \multirow{2}{*}{$\begin{array}{l}\text { Max. duct. } \\
\text { class }(q \\
\text { reduction } \\
\text { from } \mathrm{H})\end{array}$} & \multirow[b]{2}{*}{$\begin{array}{l}\text { Min. } h_{c} \\
{[\mathrm{~cm}]}\end{array}$} & \multicolumn{6}{|c|}{ Max. $w$ (outer part of $b_{w}$ ) for } & \multirow[b]{2}{*}{$\begin{array}{l}\text { \% upper } \\
\text { reinf. within } \\
\text { column core }\end{array}$} \\
\hline & & & & & & & & & & Member web & $\begin{array}{l}\text { Reinf. } \\
\text { (both } \\
\text { sides) }\end{array}$ & $\begin{array}{l}\text { Edge beam } \\
b_{b} \text { from } \\
\text { max. } e\end{array}$ & $\begin{array}{l}\text { Joint } \\
\text { shear }\end{array}$ & $\begin{array}{c}\text { Upper slab tension } \\
\text { flange reinforcement }\end{array}$ & $\begin{array}{l}\text { Beam } \\
\text { shear }\end{array}$ & \\
\hline \multicolumn{2}{|c|}{$\begin{array}{l}\text { Greece: EAK (2000), EKOS } \\
\text { (2000) }\end{array}$} & 1.25 & - & $\begin{array}{l}\text { stiffness } \\
\text { required } \\
(5)\end{array}$ & \multicolumn{2}{|c|}{$\mathrm{DCH}(q=3.5)$} & $\begin{array}{l}\text { stiffness } \\
\text { required }\end{array}$ & $\begin{array}{c}\mathrm{DCH} \\
(q=3.5)\end{array}$ & (25) & $\begin{array}{c}\min \left\{0.25 h_{c}\right. \\
\left.0.5 b_{c}\right\}^{(8,9)}\end{array}$ & - & $0.66 b_{c}$ & - & $h_{f}\{0 ; 2 ; 2.5 ; 4\}^{(17)}$ & $-(21)$ & - \\
\hline \multicolumn{2}{|c|}{$\begin{array}{l}\text { New Zealand: NZS } 1170.5 \\
\text { (2004), NZS } 3101 \text { (2006) }\end{array}$} & $2.5^{(2)}$ & - & $\begin{array}{c}\text { IDR } \leq 0.9 \\
\%\end{array}$ & \multicolumn{2}{|c|}{$\begin{array}{c}\operatorname{DCL}(q=1.25 ; \\
-79 \%)\end{array}$} & $\begin{array}{c}\approx 27 \phi_{c} \approx \\
43^{(6,7)}\end{array}$ & $\begin{array}{c}\mathrm{DCH} \\
(q=3.5)\end{array}$ & $\begin{array}{l}\approx 30 \phi_{w i} \\
\approx 48^{(6,7)}\end{array}$ & - & $0.25 h_{c}^{(9,11)}$ & $0.25 h_{c}$ & $\underset{(16)}{0.25 h_{c}}$ & $\begin{array}{c}\min \left\{L / 8 ; 8 h_{;} h_{b} ;\right. \\
\left.h_{c} \cdot\{0.5 ; 0.75\}^{(18)}\right\} \\
\min \left\{L / 8 ; 8 h_{f} ; 3 h_{b}\right\}^{(19)}\end{array}$ & $\left(\begin{array}{c}(22) \\
\left(25 h_{c}\right.\end{array}\right.$ & $90 \%{ }^{(24)}$ \\
\hline \multicolumn{2}{|c|}{$\begin{array}{l}\text { Spain: NCSE-02 (2002), } \\
\text { EHE-08 (2008) }{ }^{*}\end{array}$} & - & - & - & \multicolumn{2}{|c|}{$\begin{array}{c}\text { DCL }(q=2 ; \\
-50 \%)\end{array}$} & - & $\begin{array}{c}\text { DCL }(q=2 ; \\
-50 \%)\end{array}$ & (25) & - & $0.0 ; 0.5 h_{b}{ }^{(12)}$ & $0.5 b_{c}$ & - & $h_{f}\{0 ; 2 ; 2 ; 4\}$ & $0.0^{(23)}$ & - \\
\hline \multicolumn{2}{|c|}{$\begin{array}{l}\text { Italy: } \\
\text { NTC (2008) }\end{array}$} & $\approx 1.3^{(3)}$ & - & - & \multicolumn{2}{|c|}{$\begin{array}{c}\text { DCH } \\
(q=5.85)\end{array}$} & - & $\begin{array}{c}\text { DCM }(q=3.9 ; \\
-33 \%)\end{array}$ & $\begin{array}{l}\approx 36 \phi_{w i} \\
\approx 55^{(6,7)}\end{array}$ & $\begin{array}{l}\min \left\{0.5 h_{b} ;\right. \\
\left.0.5 b_{c}^{(8)}\right\}^{(10)}\end{array}$ & - & $0.5 b_{c}^{(14)}$ & $\underset{(8)}{0.25 h_{c}}$ & $h_{f}\{0 ; 2 ; 0 ; 2\}^{(17)}$ & $-(21)$ & $75 \%$ \\
\hline \multicolumn{2}{|c|}{$\begin{array}{l}\text { Europe: } \\
\text { EC8 (2004) }\end{array}$} & 1.0 & $\begin{array}{c}\min \{0.08 \\
0.1 / \mathrm{S}\}\end{array}$ & - & \multicolumn{2}{|c|}{$\begin{array}{c}\text { DCL }(q=1.5 ; \\
-74 \%)\end{array}$} & - & $\begin{array}{c}\text { DCH } \\
(q=5.85)\end{array}$ & $\begin{array}{l}\approx 36 \phi_{w i} \\
\approx 55^{(6,7)}\end{array}$ & - & $\begin{array}{c}\min \left\{0.5 h_{b} ;\right. \\
\left.0.5 b_{c}\right\}^{*(8,9,13)}\end{array}$ & $0.5 b_{c}$ & $\underset{(8)}{0.25 h_{c}}$ & $h_{f}\{0 ; 2 ; 2 ; 4\}^{(17)}$ & - & - \\
\hline \multicolumn{2}{|c|}{$\begin{array}{l}\text { Turkey: } \\
\text { TSI (2007) }\end{array}$} & 2.0 & 0.20 & $\mathrm{H} \leq 13 \mathrm{~m}$ & \multicolumn{2}{|c|}{$\begin{array}{c}\text { DCM }(q=4 ; \\
-50 \%)\end{array}$} & $\begin{array}{c}\min \left\{3 h_{f}\right. \\
30\}\end{array}$ & $\begin{array}{l}\mathrm{DCH} \\
(q=8)\end{array}$ & (25) & $0.5 h_{b}^{(8)}$ & - & - & 0.0 & - & $-^{(21)}$ & - \\
\hline \multicolumn{2}{|c|}{$\begin{array}{l}\text { USA: ASCE/SEI 7-10 } \\
\text { (2010), ACI 318-08 (2008), } \\
\text { ACI 352R-02 (2002) }{ }^{*}\end{array}$} & $\begin{array}{l}1.0- \\
2.5^{(4)}\end{array}$ & - & - & \multicolumn{2}{|c|}{$\begin{array}{c}\operatorname{DCM}(q=4 ; \\
-38 \%)\end{array}$} & - & $\begin{array}{l}\mathrm{DCH} \\
(q=8)\end{array}$ & $\begin{array}{l}20 \phi_{w_{0}} \\
\approx 32^{(7)}\end{array}$ & $\min \left\{0.75 h_{c}\right.$ & - & (15) & 0.0 & $\begin{array}{c}\min \left\{L / 20-b_{w} / 2 ; 8 h_{f}\right\} \\
\min \left\{L / 8-b_{w / 2} / 2 ; 8 h_{f}\right. \\
\left.h_{c}\right\} \geq 2 b_{b}(19)(20)\end{array}$ & -(21) & $33 \%$ \\
\hline $\begin{array}{l}\text { (1) } \\
\text { (2) } \\
\text { (3) } \\
\text { (4) } \\
\text { (5) } \\
\\
\text { (6) }\end{array}$ & $\begin{array}{l}\text { Recommendations, not } \\
\text { For DLS but obtained } \\
\text { Specific for ULS } \\
\text { Obtained from specifi } \\
\text { Depending on } a_{g} \text { and } \mathrm{n} \\
\text { Sufficient stiffness to } \\
\text { columns } \\
\text { Formulation dependin } \\
\text { strengths, axial load, } \mathrm{r} \\
\text { Considering } \phi_{w}=16 \mathrm{mn} \\
\text { Edge beams not explic } \\
\text { Not for low-ductility }\end{array}$ & $\begin{array}{l}\text { mandatory } \\
\text { rom ULS } \\
\text { DLS dem } \\
\text { umber of st } \\
\text { nsure fram } \\
\text { in most of } \\
\text { inforceme } \\
\text { tly conside } \\
\text { esign }\end{array}$ & $\begin{array}{l}\text { lacements } \\
\text { spectrum } \\
\text { s } \\
\text { ot cantilever- } \\
\text { cases on ducti } \\
\text { tios and locatic }\end{array}$ & $\begin{array}{l}\text { ohaviour it } \\
\text { ty class, ma } \\
\text { of the join }\end{array}$ & & $\begin{array}{l}\text { (11) } \\
\text { (12) }\end{array}$ & $\begin{array}{l}\text { Referred to } \\
\text { Referred to } t \\
\text { remaining 11 } \\
\text { Required tra } \\
\text { connections } \\
\text { Not mandatc } \\
\text { compression } \\
\text { Higher value } \\
\text { placed } \\
\text { Further rese } \\
\text { Also recipro } \\
\text { column - na }\end{array}$ & $\begin{array}{l}\text { ross section, not } t \\
\text { ne } 90 \% \text { of the req } \\
\% \text { within (19) } \\
\text { isverse beam for } \\
\text { with moment inve } \\
\text { y, only for taking } \\
\text { on the bond beha } \\
\text { only if proper p } \\
\text { rch is needed } \\
\text { al requirement fo } \\
\text { row beam connec }\end{array}$ & $\begin{array}{l}\text { web } \\
\text { red flexural } \\
\text { ternal conn } \\
\text { ion } \\
\text { dvantage o } \\
\text { our } \\
\text { pendicular } \\
\\
\text { columns in } \\
\text { on }\end{array}$ & $\begin{array}{l}\text { reinforcement; } \\
\text { ctions or internal } \\
\text { the column } \\
\text { einforcement is } \\
\text { he case of wide }\end{array}$ & $\begin{array}{l}(18) \\
(19) \\
(20) \\
(21) \\
(22) \\
(23) \\
\\
(24)\end{array}$ & $\begin{array}{l}\text { Exterior conne } \\
\text { interior connee } \\
\text { Exterior conne } \\
\text { For beam flex } \\
\text { joint designing } \\
\text { Torsional eval } \\
\text { Maximum } b_{w} \\
\text { Uncertain, not } \\
\text { Value at the cc } \\
\text { column face; } i \\
\text { Not column cc } \\
\text { lower values }\end{array}$ & $\begin{array}{l}\text { ion with } \\
\text { on, respe } \\
\text { ion with } \\
\text { al design } \\
\text { respectiv } \\
\text { tion of s } \\
\text { nitation I } \\
\text { xplicitly } \\
\text { imn face } \\
\text { ermediat } \\
\text { a but join }\end{array}$ & $\begin{array}{l}\text { and without transverse } b \\
\text { ctively } \\
\text { and without transverse b } \\
\text { ng and for overstrength } \\
\text { ly } \\
\text { andrel beam in external } \\
\text { nay control both flexural } \\
\text { ndicated } \\
0.5 h_{b} \text { at distance of high } \\
\text { values from linear inter } \\
\text { effective width; strut-an }\end{array}$ & $\begin{array}{l}\mathrm{m} \text {, and an } \\
\mathrm{m} \text {, respect } \\
\text { aluation } \mathrm{fc} \\
\text { nnections } \\
\text { dd shear be } \\
\text { than } 0.5 \mathrm{~h} \\
\text { lation } \\
\text { tie analys }\end{array}$ & $\begin{array}{l}\text { gous for } \\
\text { ely } \\
\text { column and } \\
\text { equired } \\
\text { aviour } \\
\text { rom the } \\
\text { required for }\end{array}$ \\
\hline $\begin{array}{l}a_{g} \\
\mathrm{~S} \\
\mathrm{H} \\
L \\
\mathrm{IDR} \\
\end{array}$ & $\begin{array}{l}\text { Design ground acce } \\
\text { Soil amplification } \mathrm{f} \\
\text { Building height } \\
\text { Beam span } \\
\text { Interstorey drift } \\
\end{array}$ & $\begin{array}{l}\text { eration } \\
\text { ctor }\end{array}$ & $\begin{array}{l}\text { DCH } \\
\text { DCM } \\
\text { DCL } \\
q \\
w \\
\end{array}$ & $\begin{array}{l}\text { High Duc } \\
\text { Medium I } \\
\text { Low Duc } \\
\text { Behaviou } \\
\text { Outer can }\end{array}$ & $\begin{array}{l}\text { lity Cl } \\
\text { uctility } \\
\text { lity Cl } \\
\text { factor } \\
\text { llevere }\end{array}$ & & respect to nar & ower column cor & $\begin{array}{l}b_{b} \\
b_{w} \\
h_{b} \\
b_{c} \\
h_{c} \\
\end{array}$ & $\begin{array}{l}\text { Beam gross se } \\
\text { Beam web wid } \\
\text { Beam depth } \\
\text { Column width } \\
\text { Column depth } \\
\end{array}$ & $\begin{array}{l}\text { ction width } \\
\text { lth }\end{array}$ & $\begin{array}{l}h_{f} \\
e \\
\phi_{c} \\
\phi_{w i} \\
\phi_{w o} \\
\end{array}$ & $\begin{array}{l}\text { Upper s } \\
\text { Beam - } \\
\text { Maxim } \\
\text { Maxim } \\
\text { Maxim } \\
\end{array}$ & $\begin{array}{l}\text { ab tension flange thickn } \\
\text { column eccentricity } \\
\text { m column bar diameter } \\
\mathrm{m} \text { beam bar diameter pa } \\
\mathrm{m} \text { beam bar diameter pa }\end{array}$ & $\begin{array}{l}\text { ing throug } \\
\text { ing outsid }\end{array}$ & $\begin{array}{l}\text { the joint } \\
\text { he joint }\end{array}$ \\
\hline
\end{tabular}

(a)

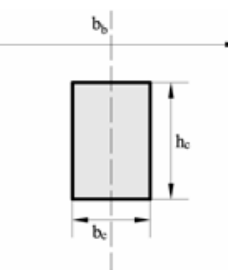

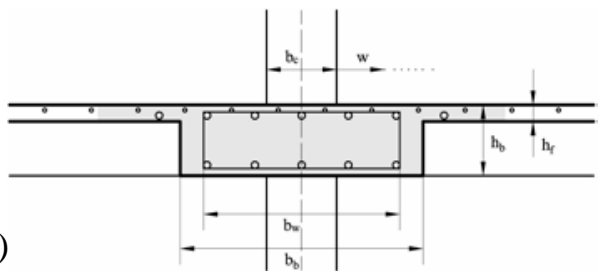

(c)

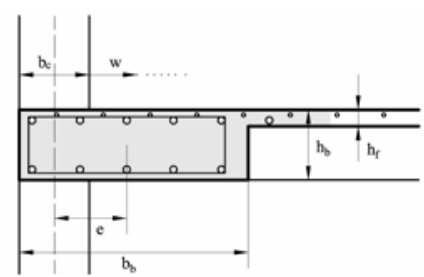

Fig. 1: Graphic description of variables used in Table 1, corresponding to: plan of interior connection (a), and elevation of connection belonging to central (b) and edge (c) frame 


\section{EXPERIMENTAL BEHAVIOUR AND ANALYTICAL MODELS OF WBF}

Experimental tests on WB and WBF have been representing the benchmark for changes and improvements to codes in the last decades. Several cyclic tests on subassemblages representing WB-C connections have been carried out (Gentry and Wight, 1992; LaFave and Wight, 1997; Quintero-Febres and Wight, 1997; Siah et al., 2003; Benavent-Climent, 2007; Benavent-Climent et al., 2009 and 2010; Li and Kulkarni, 2010, Masi et al., 2013a and 2013b; Fadwa et al., 2014). All these studies capture different conditions (e.g., interior or exterior connections, presence of upper slab, axial load on columns, vertical load on beams, or transverse deep beams). Furthermore, post-earthquake damage scenarios in the Mediterranean area have shown different in-field performance of WBF with respect to that of DBF. For instance, plastic hinges in beams and damage in joints are quite rarely observed (e.g., Donmez, 2013; Gómez Martínez et al., 2015a).

Aimed at shedding some light on code provisions, a review of experimental and analytical studies and original mechanic and analytical considerations on WBF are provided herein. The study is carried out in three main steps, from local to global performances, in analogy with the main three drawbacks characterizing WBF with respect to DBF (Benavent et al., 2010): (i) deficient beam-column stress transfer, (ii) poorer local ductility of beams, and (iii) lower lateral stiffness.

\subsection{Equilibrium of forces in wide beam column connections}

On the topic of local behaviour of WB-C connections, most of the aforementioned works have enlightened that the portion of forces (moment and shear) corresponding to the fraction of beam section passing outside the column core (called herein "outer" part of the section) can be equilibrated only if the transverse beam develops sufficient torsional behaviour; otherwise, full beam section capacities are not attained and brittle behaviour is expected. Moreover, if longitudinal bars passing outside the column core are not adequately bonded, not even maximum flexural capacities of WB are transmitted to the transverse beam. On the other hand, WB-C connections generally show higher contribution of the upper slab and better shear performance of joints and beam ends than deep beam-column (DB-C) connections (LaFave and Wight, 1997).

Most of these phenomena can be reproduced with different strut-and-tie mechanisms, as shown for a typical 3D sub-assemblage of interior WB-C connection with upper slab and 
transverse beam in Fig. 2. Herein, the strut-and-tie model in Fig. 2 is the basis of authors' theoretical interpretation of experimental behaviour of WB-C connections.
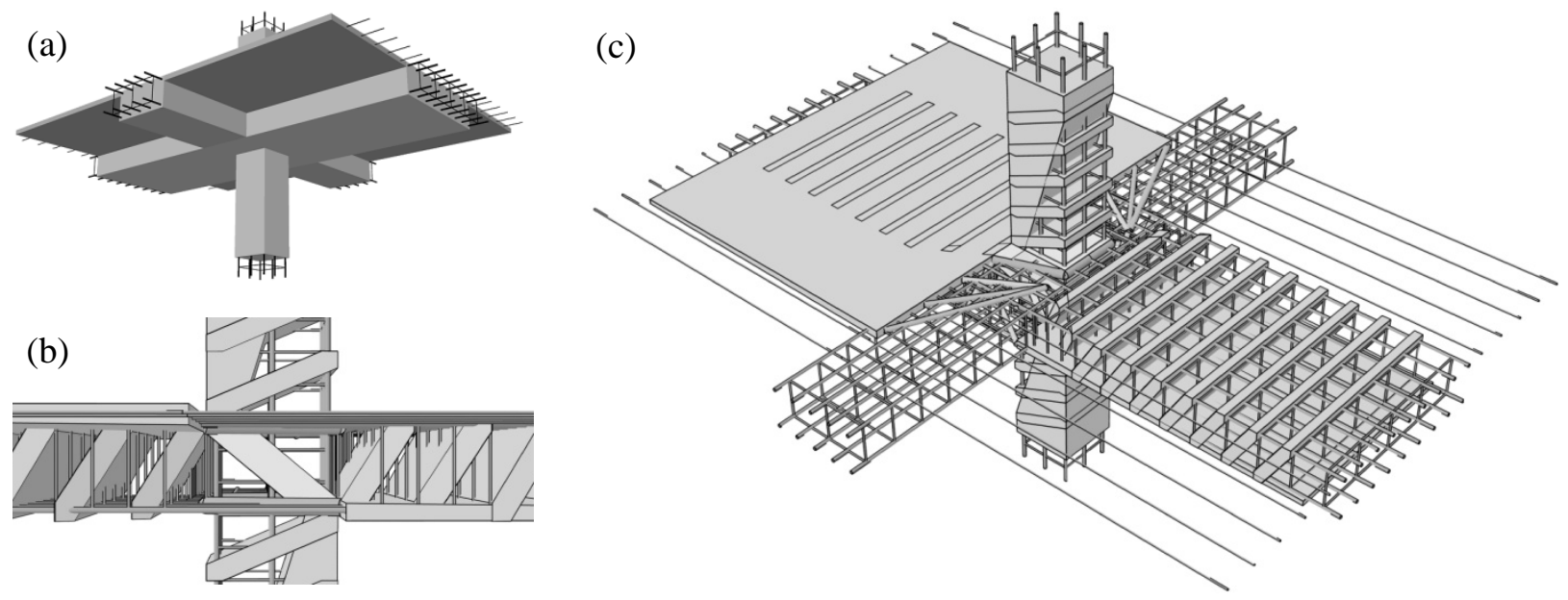

(b)

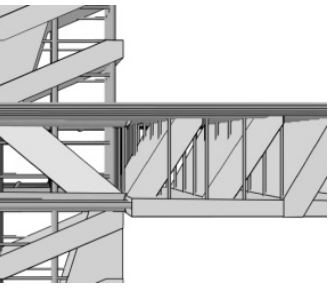

Fig. 2: 3D subassemblage of typical WB - column connection: solid view (a) and strut-and-tie scheme (b and c)

Regarding bending moment equilibrium, the opposite horizontal forces developed at the upper and lower regions of the beam section corresponding to its outer part (at both sides of the column core) must be transferred to the joint through a torsion path in the perpendicular direction. This path can be developed by an explicit member -transverse beam - or by both concrete and reinforcement belonging to the longitudinal beam. Internal connections without moment inversion do not require any transverse torsion.

However, the aforementioned experimental studies showed that not all the forces of the outer part of the beam need full transverse torsion to be equilibrated. The fraction of horizontal forces closer to the core -within the effective width - is able to be transmitted to the joint panel straightaway. Two different strut-and-tie models can be inferred from those studies:

a) independent from the joint path: horizontal compressed struts tied by the reinforcement in the transverse direction (Fig. 3a);

b) integrated within the joint path: fusiform joint diagonal strut flowing between opposite stress blocks of column and beam (Fig. 3b), which may be assumed to develop in both directions, resulting in a superposition of two trapezoidal struts (Fig. 3c). 

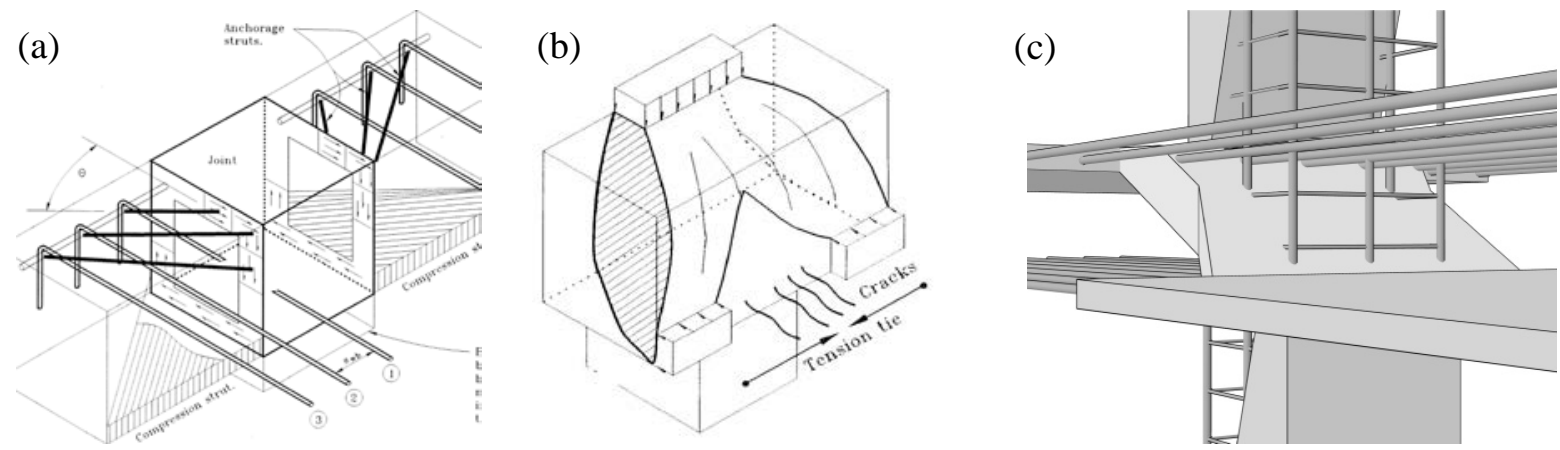

Fig. 3: Different strut-and-tie models for the flexural equilibrium of the outer part of the beam section within the effective width: independent from the joint (a, from Gentry and Wight, 1992); and integrated within the joint, trapezoidal (b, from Gentry and Wight, 1992) or bi-trapezoidal (c)

Outside of the effective width, sufficient torsional capacity in the transverse beam is required for the development of full flexural capacity of longitudinal beams (Fig. 4a); otherwise, incomplete plastic hinges are developed and brittle torsional failure can lead to poorer cyclic performances. If the torsional demand exceeds the cracking torque, large drifts are needed to attain the yielding of the longitudinal reinforcement. Such phenomenon experimentally results in lower equivalent stiffness and pinching of the hysteresis loops. In interior connections with moment inversion, torsional performance may not be the weakest mechanism because the upper slab contribution increases torsional capacity (Gentry and Wight, 1992). Most codes do not require any torsional evaluation because this issue is overcome by limiting $b_{w}$ to the effective width.

On the other hand, the attainment of beam full flexural capacities requires proper bond behaviour of longitudinal bars. Most of the aforementioned experimental works suggest that slippage is more likely to occur in WB than in DB, especially in bars passing outside the column core -which may not benefit from column compression. Another cause of poorer bond behaviour in WB with respect to DB can be the likely higher initial cracking due to gravitational loads. It is worth noting that hoops placed at both sides of the column increase slightly bond conditions of the longitudinal bars (Quintero-Febres and Wight, 2001).

Regarding joint mechanism, experimental results show that joint diagonal concrete strut may extend laterally to both sides, thus expanding the joint effective shear area (Fig. 4c). This assumption is also geometrically coherent with the alternative bi-trapezoidal model (Fig. 3c). However, not all the codes suggest an enlargement of design joint effective width (Fig. 4b). 
LaFave and Wight (1997) demonstrate that joint effective width may be higher for WB than for $\mathrm{DB}$, thus limiting joint cracking and stiffness deterioration in WB subassemblage. One of the causes might be that the joint panel is totally included within the thickness of the slab in the case of WBF, which can improve the confinement of the strut. Besides, stirrups in the outer part of the beam might increase the confinement of the joint enlarged strut (Quintero-Febres and Wight, 2001).
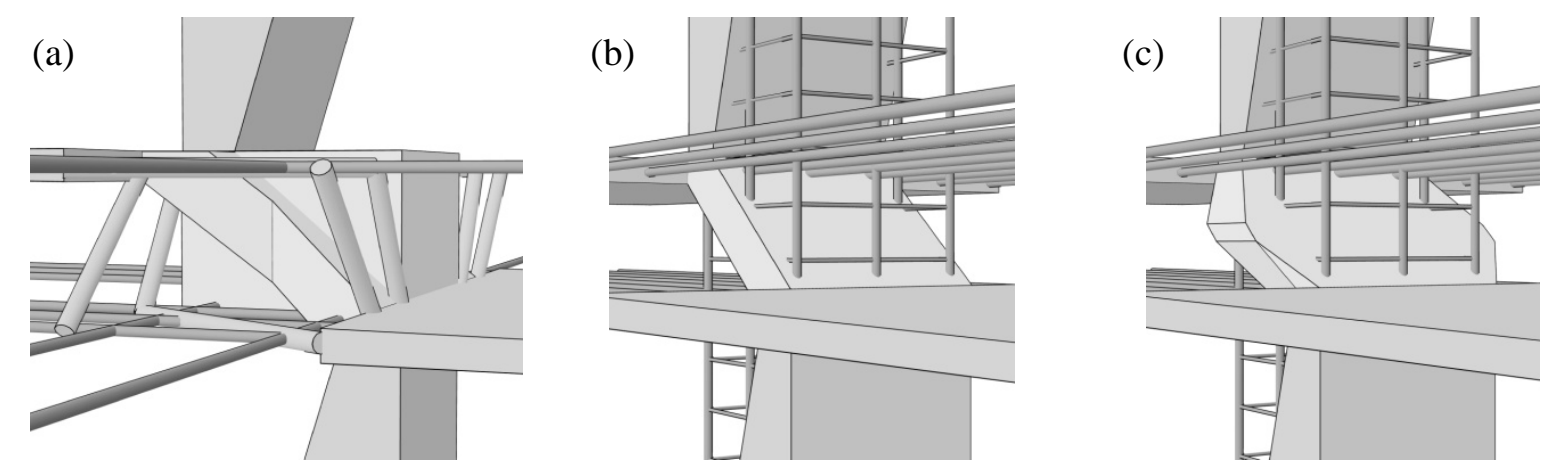

Fig. 4: Strut-and-tie model of the torsional mechanism outside effective width (a); and ACI 318-08 (b) and NZS 3101 (c) models for joint compressed strut.

Furthermore, also the contribution of the upper slab can be modelled through a strut-andtie mechanism (Fig. 5a). However, determination of the effective width of the upper slab is not trivial, because there is no agreement in its definition and it increases with IDR (i.e. depends on demand). Experimental studies (Cheung et al., 1991; Kurose et al., 1991; La Fave and Wight, 1999) show that the larger is the drift demand, the higher is the slab portion involved in flexural regime (Figs. 5b and 5c)

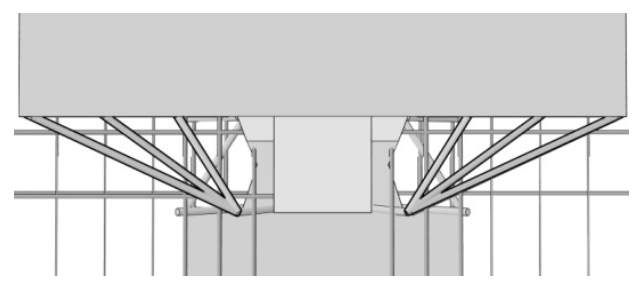

(a)

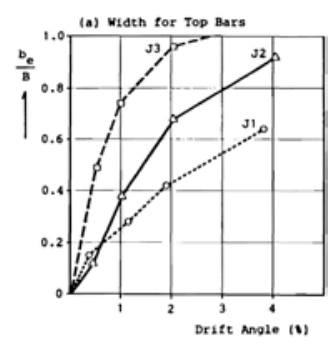

(b)

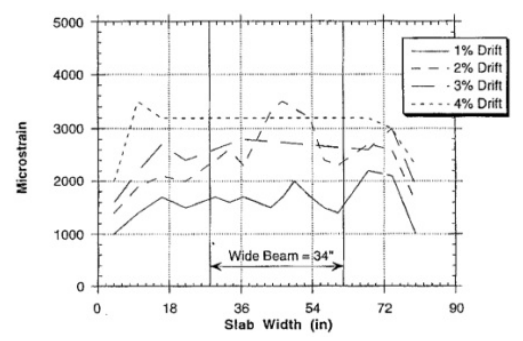

(c)

Fig. 5: Strut-and-tie model representing upper slab contribution (a) and increase of upper slab effective width for larger drifts according to Kurose et al. (1991) (b) and LaFave and Wight (1999) (c) 
Codes allow accounting for the maximum strength of the reinforcement placed within the effective width of the upper slab, assuming implicitly that this capacity is equivalent to the real one, which is not uniform but decreasing from the column axis, within a portion of slab larger than the effective width. The above definition may have its origin in the evaluation of the contribution or compressed concrete for positive bending moment, in which the compression capacity is constant; however, for negative bending the tension capacity is non-uniform because almost all the reinforcement is near the beam. Thus, relying on the full tension capacity within the effective width may be not conservative for flexural purposes, and conservative for capacity design purposes.

Concerning the different contribution of the upper slab in WB compared to DB, experimental results presented in LaFave and Wight (1997) show values of total effective width about 30\% higher for WB than for DB (Fig. 6). Conversely, if only the outer part of the slab is considered (i.e. measured from the lateral face of the beam) DB show values 35\% larger than WB. The first size may be representative for negative moment, as it considers all the reinforcement contained in the slab; instead, the second measurement may be representative of positive moment, as it only considers the increment of width of the stress block. All in all, upper slab contribution seems to be similar for both structural solutions if measured from the end of the beam effective width. It is coherent with the assumption of the strut-and-tie model shown in Fig. $5 a$, in which the maximum strut angle is measured from the border of the joint strut, i.e. from the end of the effective width of the beam.
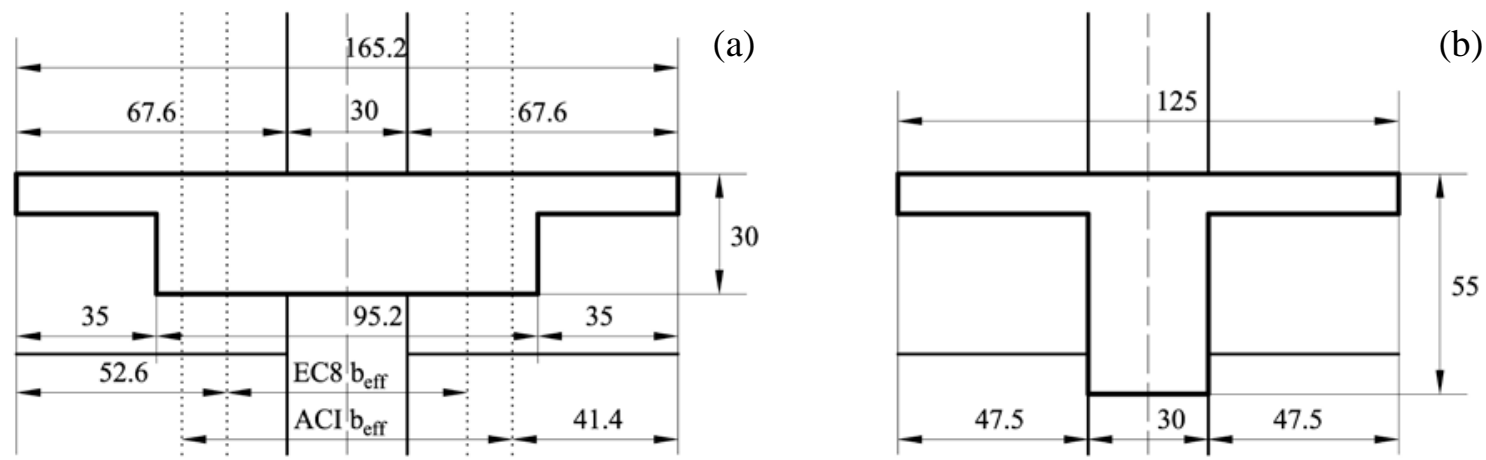

Fig. 6: Upper slab effective width for WB (a) and DB (b) specimens (adapted from LaFave and Wight, 2001) 
All the values for upper slab effective width given by codes and experimental studies are referred to Ultimate Limit State (ULS) design. No reference is given to the contribution of upper slab to initial uncracked stiffness of the structure for Serviceability Limit State (SLS).

Regarding equilibrium of shear forces, some experimental works on WB-C subassemblages subjected to static gravitational loads (Serna-Ros et al., 2001; and Shuraim, 2012) have shown that regular distribution of stirrup legs within $b_{w}$ increases shear strength, and effectiveness of stirrups legs decreases with the distance from column core. Conversely, LaFave and Wight (1997) observed that similar transversal reinforcement ratios in WB and DB lead to lower shear cracking and shear deformation near the column for WB specimens.

\subsection{Ductility}

Lack of local ductility (i.e. low chord rotation ductility, $\mu_{\theta}$, for elements) or lack of global ductility (i.e., impossibility to develop global collapse mechanism) are generally the reasons for any $q$ reductions in codes. Traditionally, curvature ductility $\left(\mu_{\phi}\right)$ of WB has been considered to be lower than that of DB (Paulay and Priestley, 1992), based on generic considerations in which confinement is not taken into account. Parametric studies affecting chord rotations of wide beams according to different codes recently appeared in literature (e.g., Tore and Demiral, 2014); however, a parametric comparison between WB and DB has not yet systematically performed. Evaluation of local ductility of WB with respect to DB depends on relationships between ultimate $\left(\theta_{u}\right)$ and yielding $\left(\theta_{y}\right)$ chord rotation, which in turn depend on analogous curvatures ( $\phi_{u}$ and $\phi_{y}$, respectively).

Herein a parametric study is provided for a straightforward comparison between confined WB and DB. Eight couples of DB and WB corresponding to similar flexural resistances are considered, varying geometry and reinforcements. Then, $\phi_{y}, \phi_{u}, \theta_{y}, \theta_{u}, \mu_{\phi}$ and $\mu_{\theta}$ are evaluated according to different formulations and then compared. Shear span length of $2.5 \mathrm{~m}$, concrete covering of $20 \mathrm{~mm}$ and mean diameter of longitudinal bars of $14 \mathrm{~mm}$ are assumed for all the beams. Mean resistances of materials $\left(f_{c m}=33 \mathrm{MPa}\right.$ and $f_{y m}=630 \mathrm{MPa}$ for concrete and steel, respectively) correspond to characteristic values typical of current Spanish building stock ( $f_{c k}=25 \mathrm{MPa}$ and $f_{y k}=500 \mathrm{MPa}$ for concrete and steel, respectively).

Four parameters are assumed: (i) class (DB or WB); (ii) cross-sectional aspect ratio (types A and B, providing higher or lower bending moment resistances, respectively); (iii) top-tobottom reinforcement ratio (1:1 or 3:2); and (iv) total reinforcement ratio (high and low, which 
makes top and bottom reinforcement, respectively, correspond to code's upper and lower limit, when top-to-bottom ratio is 3:2). Reinforcement arrangements are selected in order to obtain similar moment resistances between analogous deep and wide beams, resulting in total reinforcement ratios in WB approximately twice the reinforcement in DB (almost similar to the ratio between effective depths). In each case, high reinforcement case provides approximately three times the flexural strength provided by low reinforcement case. Common stirrup arrangements, according to Eurocode 2 prescriptions (BSI, 2004), are considered. Characteristics of the different elements are shown in Table 2, being: $\omega, \omega^{\prime}$ and $\omega_{\text {tot }}$, bottom, top and total mechanical reinforcement ratio; $\rho_{w}$, transverse reinforcement ratio; and $M_{y}$, yielding moment resistance.

Table 2: Characteristics of the analysed set of beams

\begin{tabular}{|c|c|c|c|c|c|c|c|c|c|c|c|c|c|c|c|c|c|}
\hline \multirow{5}{*}{$\begin{array}{c}\text { Class } \\
\text { of } \\
\text { beam }\end{array}$} & \multicolumn{3}{|c|}{ Geometry } & \multicolumn{2}{|c|}{$\begin{array}{c}\text { Transverse } \\
\text { reinforcement }\end{array}$} & \multicolumn{12}{|c|}{ Longitudinal reinforcement } \\
\hline & \multirow{4}{*}{$\begin{array}{c}\text { Section } \\
\text { type } \\
(\mathrm{A} / \mathrm{B})\end{array}$} & \multirow{4}{*}{$\begin{array}{c}b_{w} \\
{[\mathrm{~mm}]}\end{array}$} & \multirow{3}{*}{$h_{b}$} & \multirow{3}{*}{ Hoops } & \multirow[b]{4}{*}{ [\%] } & \multicolumn{6}{|c|}{ Low } & \multicolumn{6}{|c|}{ High } \\
\hline & & & & & & \multirow{3}{*}{$\omega_{t o t}$} & \multicolumn{3}{|c|}{$\omega^{\prime} / \omega=1.5$} & \multicolumn{2}{|c|}{$\omega^{\prime} / \omega=1$} & \multirow{3}{*}{$\omega_{\text {tot }}$} & \multicolumn{3}{|c|}{$\omega^{\prime} / \omega=1.5$} & \multicolumn{2}{|c|}{$\omega^{\prime} / \omega=1$} \\
\hline & & & & & & & \multicolumn{2}{|c|}{ Reinf. ratio } & $M_{y}$ & & $M_{y}$ & & \multicolumn{2}{|c|}{ Reinf. ratio } & \multirow{2}{*}{$\begin{array}{c}M_{y} \\
{[\mathrm{kNm}]}\end{array}$} & \multirow{2}{*}[\%]{} & $M_{y}$ \\
\hline & & & [mm] & {$[\mathrm{mm}]$} & & & & \%] & {$[\mathrm{kNm}]$} & {$[10]$} & [kNm] & & & o] & & & {$[\mathrm{kNm}]$} \\
\hline \multirow{4}{*}{ DB } & \multirow{2}{*}{ A } & \multirow{2}{*}{300} & \multirow{2}{*}{600} & \multirow{4}{*}{$2 \phi 8 / 70$} & \multirow{4}{*}{0.48} & \multirow{4}{*}{0.10} & $\rho^{\prime}$ & & -181 & \multirow{2}{*}{0.25} & \multirow{2}{*}{ \pm 152} & \multirow{4}{*}{0.29} & $\rho^{\prime}$ & 0.90 & -524 & \multirow{2}{*}{0.75} & \multirow{2}{*}{ \pm 442} \\
\hline & & & & & & & $\rho$ & 0.20 & +122 & & & & $\rho$ & 0.60 & +357 & & \\
\hline & \multirow{2}{*}{ B } & 200 & 500 & & & & $\rho^{\prime}$ & 0.30 & -124 & - & 104 & & $\rho^{\prime}$ & 0.90 & -357 & & \\
\hline & & 500 & 500 & & & & $\rho$ & 0.20 & +84 & 0.25 & -104 & & $\rho$ & 0.60 & +244 & 0.15 & \pm 301 \\
\hline & A & 650 & 300 & & 0.44 & 019 & $\rho^{\prime}$ & 0.60 & -177 & 0.50 & +149 & 060 & $\rho^{\prime}$ & 1.89 & -513 & 150 & +446 \\
\hline WB & & & & $4 \phi 8 / 70$ & ד. & 0.10 & $\rho$ & 0.40 & +120 & 8.00 & 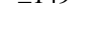 & 0.00 & $\rho$ & 1.26 & +362 & 1.00 & -170 \\
\hline & $B_{1}$ & 500 & 300 & & 057 & 017 & $\rho$ & 0.54 & -123 & 0.45 & +103 & 053 & $\rho^{\prime}$ & 1.65 & -355 & 138 & 301 \\
\hline & $D$ & 500 & 500 & & 0.57 & $0.1 \%$ & $\rho$ & 0.36 & +83 & $0.4 \mathrm{~J}$ & 1100 & 0.03 & $\rho$ & 1.10 & +244 & 1.00 & 1001 \\
\hline
\end{tabular}

Values of curvature and moments are obtained by means of a fibre model; mechanical model proposed in EC8 part 3 -EC8-3 in the following- (CEN, 2005) is adopted for concrete. Two different codes are adopted aimed at chord rotation calculation: EC8-3 and American ASCE SEI/41-06 -ASCE in the following- (ASCE, 2007). The first one provides explicit formulations for $\theta_{y}$ and $\theta_{u}$; for ultimate value, two different formulations are suggested: one "fundamental" and another one "empirical" (formulations A.4 and A.1 of the code, respectively). In ASCE, $\theta_{y}$ is obtained indirectly as the addition of flexural and shear contributions both as ratios between resistance and effective stiffness, whose values are taken from Table 6-5 of the code; and $\theta_{u}$ are obtained as the sum of $\theta_{y}$ and plastic part of ultimate chord rotation $\left(\theta_{p l}\right)$, which is taken from 
Table 6-7 of the code. Fig. 7 shows the detailed results of the parametric study. Ratios for any parameter $A$ are indicated in the text as $A_{W / D}$ (rather than using the heavier notation $A_{W B} / A_{D B}$ ), and in the bottom of graphics of Fig. 7 as W/B.

In general, when $\rho^{\prime}>\rho$, better performances are achieved (i.e. lower yielding values and higher ultimate ones) for both DB and WB. It is worth noting that the three adopted approaches (EC8 and ASCE) return very different values of $\theta$ (sometimes more than 100\%) in all the cases (Fig. 7d to 7k).

Regarding curvatures, $\phi_{y, W / D}$ (Fig. 7a) is approximately inversely proportional to the ratio between effective heights $\left(d_{W / D}\right)$, because the yielding strains at tensioned reinforcement are similar in WB and DB, and the compression zone's depths may be similar and small in comparison with $d$, due to compressed reinforcement. Thus, $\phi_{y, W / D} \approx 1 / d_{W / D}$. The same reasons explain the relative values of $\phi_{u}$ (Fig. 7b), which are also inversely proportional to $d_{W / D}$ because the confinement leads to the achievement of ultimate strains in reinforcement instead of concrete, unlike unconfined sections, in which similar concrete "stress block" may be observed for WB and DB (Paulay and Priestley, 1992). Hence, similar $\mu_{\phi}$ are observed for confined WB and DB (Fig. 7c) thanks to the contribution of transverse reinforcement.

EC8-3's results of $\theta_{y}$ (Fig. 7c) reproduce the same trend than $\phi_{y}$, because they are directly proportional except for the shear experimental term in the expression, which is the less relevant. High-reinforced sections show mean values of $\theta_{y}$ only $18 \%$ higher than low-reinforced sections, which means that the increase of secant-to-yielding stiffness of beams may be almost proportional to the increase of $\rho$. Conversely, ASCE does not consider any influence of the reinforcement in the secant stiffness; thus, $\theta_{y}$ and $M_{y}$ are always proportional. Stiffness degradation (secant-to-elastic stiffness ratio) obtained with EC8 (average 0.21) is similar to the mean value suggested in Panagiotakos and Fardis (2001) -20\% - but disaggregated values for WB (mean 0.27) are significantly higher than for DB (mean 0.16). 


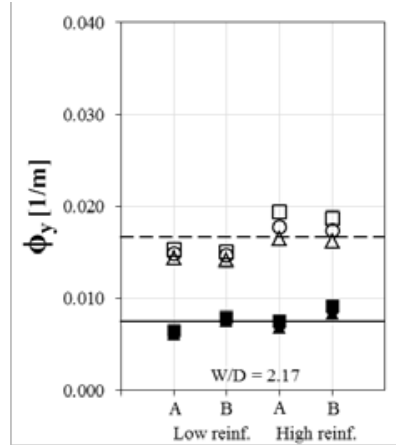

(a)

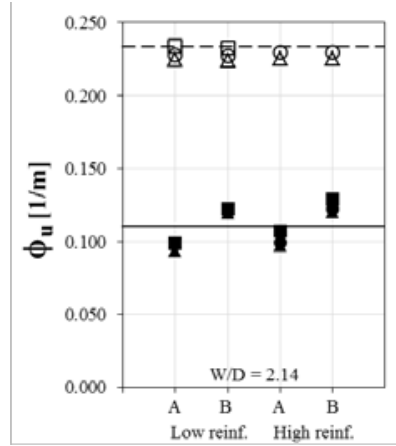

(b)

$\underline{\omega} 1 \omega$

\ DB M+ 1.5

-DB M-,+ 1.0

-DB M- 1.5

$\triangle \mathrm{WB} M+1.5$

OWB M-,+ 1.0

口WB M- 1.5

- Mean DB

- - Mean WB

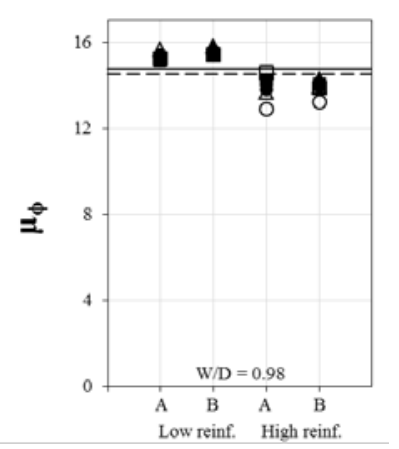

(c)

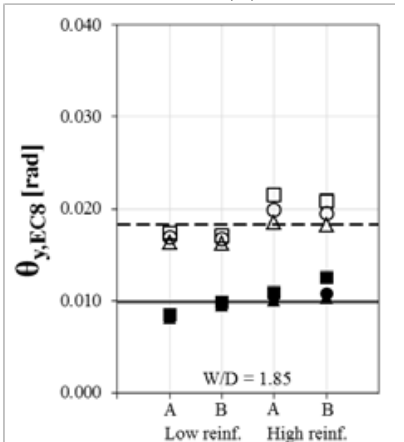

(d)

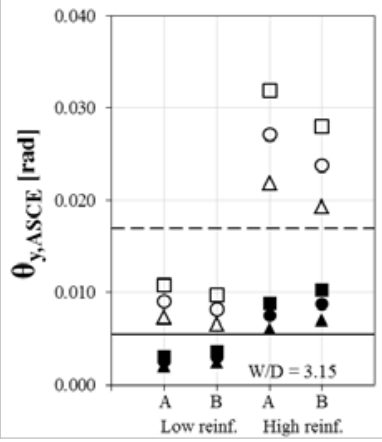

(e)

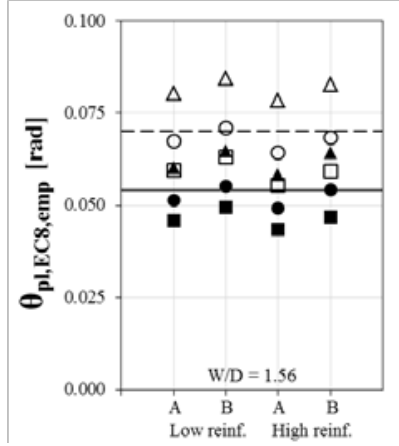

(f)

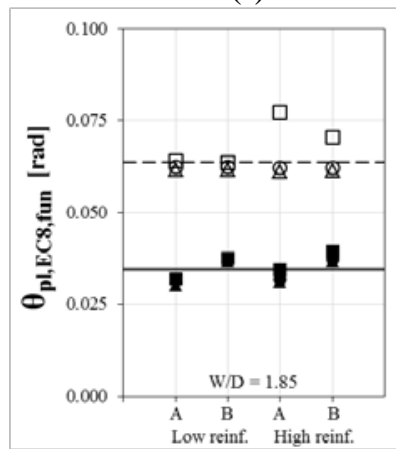

(g)

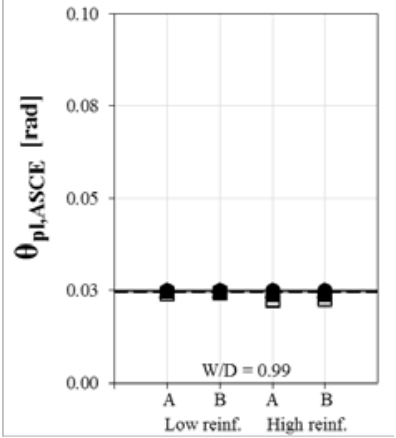

(h)

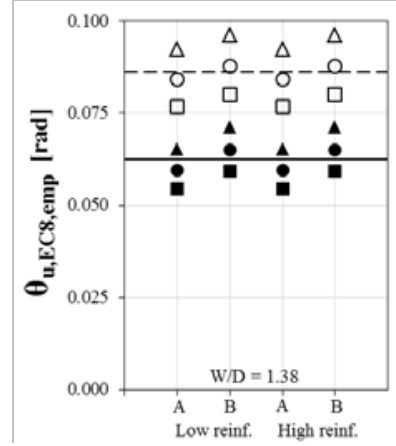

(i)

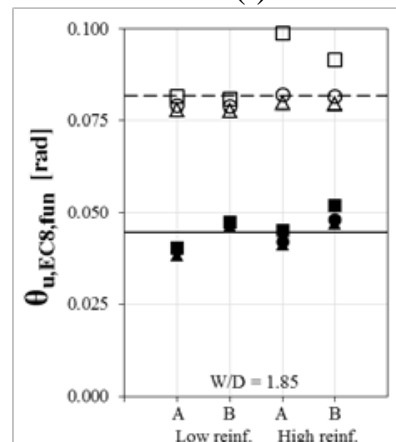

(j)

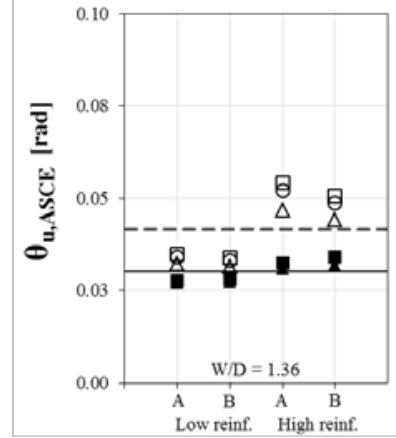

(k)

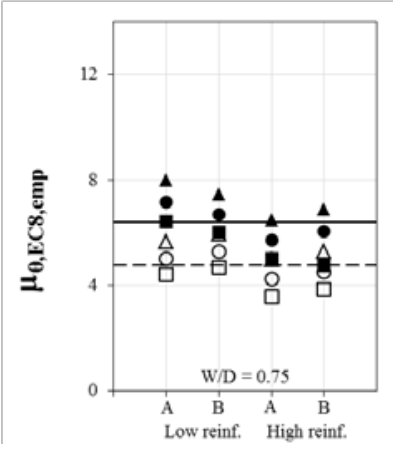

(l)

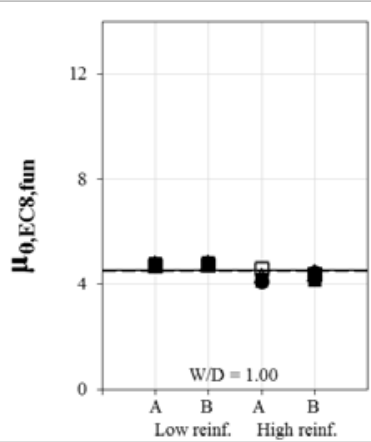

(m)

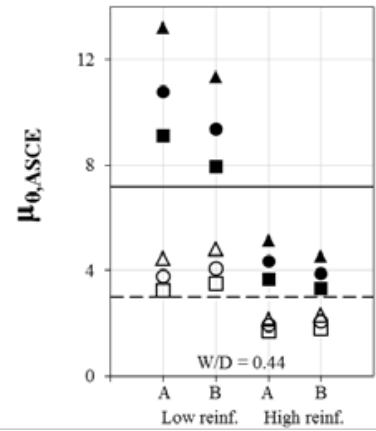

(n)

Fig. 7: Parametric analysis of local ductility of confined DB and WB: $\phi_{y}(\mathrm{a}), \phi_{u}$ (b) and $\mu_{\phi}$ (c); $\theta_{y}$ according to EC8-3 (d) and ASCE (e); $\theta_{p l}$ according to "empirical" (f) and "fundamental" (g) approaches of EC8-3, and (h) according to ASCE; and analogous for $\theta_{u}(\mathrm{i}, \mathrm{j}, \mathrm{k})$ and $\mu_{\theta}(\mathrm{l}, \mathrm{m}, \mathrm{n})$ 
Values of $\theta_{p l}$ provided by EC8-3 (Figs. 7f and 7g) are significantly larger than those provided by ASCE (Fig. 7h). For EC8-3, WB show larger values than DB, while ASCE provides similar values for both types. Still, in both approaches all values are almost independent on aspect ratio variations or total reinforcement of the section. Regarding EC8-3 "fundamental" approach (Fig. 7g), larger values are obtained for plastic hinge length of DB rather than for WB, due to higher depth: $L_{p l, W / D}=0.86$ on average, which is similar to $\theta_{p l, W / D} / \phi_{u, W / D}$. For the "empirical approach (Fig. 7f), this difference is more evident (mean 0.73).

Regarding $\theta_{u}$ (Figs. 7i, 7j and 7k) all the approaches return values significantly higher for WB than for DB (mean 38\%, 85\% and 36\% for EC8-3 “empirical”, EC8-3 “fundamental” and ASCE, respectively). The cause of such higher value of $\theta_{u, W / D}$ in EC8-3 "fundamental” approach is that confinement contribution is not accounted explicitly but it is implicitly included in $\phi_{u}$, resulting in much higher contribution for WB rather than for $\mathrm{DB}$, which also overcome the lower $L_{p l}$ for WB. Regarding the other two approaches, mean confinement contributions are larger for ASCE (1.28) than for EC8-3 “empirical” approach (1.10). In the last case, confinement contribution is higher for WB than for DB (mean 12\% larger) -because concrete core of WB is divided by stirrups in more regular areas — while ASCE return similar improvements.

Hence, very different values of local ductility ratio between WB and DB are obtained depending on the approach (see Figs. $7 \mathrm{l}, 7 \mathrm{~m}$ and $7 \mathrm{n}$ ): $\mu_{\theta, W / D}=0.75,1.00$ or 0.44 for EC8-3 "empirical”, EC8-3 "fundamental" and ASCE, respectively. Notwithstanding the important differences between approaches, it emerges that lower $\mu_{\theta}$ may be expected for WB than for DB.

In the next section it is discussed whether these local values (i.e., element level) can be directly compared with $q$ reductions (i.e., structure level) for WBF suggested by codes (e.g. 33\% and 50\% for Italian and Spanish seismic codes, respectively). This decrease of local ductility for WB with respect to DB seems to be one of the most important reasons for such code restrictions. In fact, this issue cannot be overcome by design rules, while deficient local stress transfer (see section 3.1) and lower lateral stiffness (see section 3.3) can be overcome through specific provisions.

Another key aspect for local comparison of WB and DB is the hysteretic behaviour. Cyclic energy dissipation is poorer (i.e., higher pinching) in WB rather than in DB when substandard buildings (Benavent-Climent, 2007; Benavent-Climent et al., 2009, 2010) or seismicdesigned frames with no fulfilment of EC8 width limitations (Gentry and Wight, 1992; LaFave 
and Wight, 1997; Quintero-Febres and Wight, 1997) are considered. Even in the case of EC8conforming WB-C connections, pinching is still significant (Quintero-Febres and Wight, 1997; and Li and Kulkarni, 2010). LaFave and Wight (1997) quantify such hysteretical behaviour in terms of observed equivalent viscous damping, which is $20 \%$ lower for WB subassemblages than in DB. The causes may be the poorer bond behaviour and the poorer transverse beam torsional performances of WB specimens.

On the other hand, global ductility of frames (i.e. top displacement capacity of frames) depends not only on local ductility of members but also on the ability to develop global mechanisms, which requires capacity design of columns. Experimental results on sub-standard WBF (Benavent-Climent et al., 2010) show beam-sway mechanisms even without capacity design of columns, because torsional failure of transverse beams prevent the attainment of full flexural capacities in longitudinal beams so columns get “protected”. However, this is not an advantage in terms of frame top displacement capacity since torsional failure is not ductile.

\subsection{Lateral stiffness}

Usually, WB have substantial lower member stiffness -both elastic and secant to yielding - than DB, leading to lower global stiffness of corresponding frames for similar global geometry and similar dimensions of column sections. Notwithstanding the consequent lower demands, severe disadvantages occur: (i) higher non-structural damage, and (ii) higher relevance of second order effects (P- $\Delta$ ) on columns. Lateral stiffness issue represents one of the main reasons why codes have historically limited WBF expected performances. However, as long as codes provide IDR limitations and simplified consideration of P- $\Delta$ effects, lateral stiffness is not an issue anymore as WBF must compensate the lower stiffness of beams with higher column dimensions. Only in the case of codes with no IDR limitation (such as NCSE-02) it may be reasonable to provide indirectly higher lateral stiffness to the frame through the use of very low $q$, consequently increasing strength demand and likely dimensions of elements.

As design to DLS is displacement-based, codes compel to consider kind of stiffness degradation in members up to yielding, aimed at conservativeness. However, codes suggest different reduction factors with respect to gross stiffness. EC8 suggests a reduction of 50\%; American ASCE/SEI 41-06 suggests reductions up to a 70\% for beams and 30-70\% for columns; Italian NTC from 0\% to 50\%; New Zealander NZS 3101, 60-73\% and 0-70\% for ULS beams and columns, respectively, and 0-65\% for DLS. 
On the other hand, the concerns for WBF lateral stiffness seem to be the result of the identification of WBF with flat-slab frames, which suffer strong cyclic degradation of shear capacity with the increasing ductility demand, with consequent brittle punching shear failures often observed (Pan and Moehle, 1989; and Hawkins and Michell, 1979). However, this kind of failures has no counterpart in WB sub-assemblages with code-compliant width limitations. Furthermore, code provisions regarding the predominant component of the deformed shape (i.e. shear- or cantilever-type) seems to be without any mechanical basis.

Previous considerations are consistent with the assumption that frame stiffness only depends on flexural stiffness of members, from an analytical point of view. However, experimental studies (LaFave and Wight, 2001) show that effective stiffness of WBF can be much higher than expected. The latter may be the result of (i) less cracking and deformability of the joint; (ii) higher slab participation; (iii) less shear cracking in plastic hinges; and (iv) likely higher reinforcement ratios.

\section{SIMPLIFIED SPECTRAL ESTIMATION OF RELATIVE PERFORMANCES BETWEEN DEEP- AND WIDE-BEAM FRAMES}

The spectral approach provided herein is a simplified assessment of global seismic performances of WBF with respect to DBF, finally aimed at a contextualization of code provisions regarding $q$ reduction reviewed in section 2 and experimental and analytical observations provided in section 3 .

In section 3 it is concluded that the lower $\mu_{\theta}$ of WB respect to DB is the likely reason of $q$ reduction for WBF proposed by some codes (see Table 1 and Table 3). However, $q$ is a global structural quantity and it cannot be straightforward related to $\mu_{\theta}$, which is a proxy of single element performances. In fact, $q$ not only depends on global ductility $\left(R_{\mu}\right)$ but also on other two factors: overstrength $\left(R_{S}\right)$, and demand reduction $\left(R_{D}\right)$, i.e, the ratio between strength demands corresponding to design and effective periods (Borzi and Elnashai, 2000; Mwafy and Elnashai, 2002). Furthermore, $R_{\mu}$ not only depends on local ductility of beams $\left(\mu_{\theta, b}\right)$ but also on that of columns.

All the following conditions should be satisfied in order to get a direct translation of $\mu_{\theta, \mathrm{W} / \mathrm{D}}$ of beams in the ratio between behaviour factors of WBF and DBF $\left(q_{W / D}\right)$ :

1) DBF and WBF show similar overstrength until first structural yielding and similar $R_{D}$; 
2) DBF and WBF show similar collapse of mechanisms, evaluated through the height of frame effectively involved in it $\left(H_{\text {mec }}\right)$;

3) negligible difference on first yielding displacement if observed on the capacity curve or on its piecewise linear fit;

4) the first member end yielding is a beam;

5) the first member end which reaches $\theta_{u}$ is the same beam of point 4);

6) from the attainment of first yielding all member ends (yielded or not) rotate at the same rate.

The first condition may be likely satisfied if similar strategies of design are employed. The second one depends on the column-to-beam capacity design ratio, and it, in turn, depends on section design overstrengths, which can be very different (see section 4.2). The third condition can be neglected as it is an implicit source of uncertainties even if the same fitting rule is employed for the two structures (De Luca et al., 2013). Condition 4 is plausible because of capacity design of columns. However, condition 5 and 6 can seldom be achieved. The first element reaching $\theta_{u}$ can be a column (which is the most usual situation, see section 4.2); and even if it is a beam instead, it is quite likely that a different beam reaches $\theta_{u}$. In fact, redistribution of bending moments between members cannot be really predicted a priori, and it causes nonproportional evolution of chord rotations. Hence, $\mu_{\theta, b} \neq R_{\mu} \neq q$, thus global performances of WBF are not necessarily poorer than DBF because of lower local ductility of beams.

\subsection{Safety Factor ratio}

Aimed at comparing the relative capacities of WBF and DBF, it is convenient to assess the problem in the acceleration-displacement response spectrum (ADRS) format, shifting from $q$ to PGA (Peak Ground Acceleration corresponding to the site soil) safety factor. This is only possible if spectra for different PGA are homothetic (as in EC8).

Global performance of a building could be represented by its safety factor $S F=P G A_{c} / P G A_{d}$, i.e. the ratio between capacity $\left(P G A_{c}\right)$ and demand $\left(P G A_{d}\right)$ in terms of PGA. Since $P G A_{d}$ is equal for WBF and DBF structures at the same site, the comparison of global performances can be done in terms of PGA capacity ratio of WBF and DBF $\left(P G A_{c, W / D}\right)$. The estimation of $P G A_{c}$ through spectral procedures asks for the assumption of a strength reduction factor - ductility - period $\left(R_{\mu}-\mu-T\right)$ relationship (e.g., Vidic et al. 1994; Miranda and Bertero, 1994; Vamvatsikos and Cornell, 2006), that is also the basis of behaviour factor definition. Then, 
$S F$ only depends on two variables: effective period $\left(T_{\text {eff }}\right)$ and maximum displacement capacity $\left(S_{d c}\right)$ of the equivalent single degree of freedom (SDOF), assuming that the response is controlled by a single mode. Equal-displacement rule, i.e. $T_{\text {eff }}>T_{C}$ (being $T_{C}$ the period corresponding to the end of the constant-acceleration branch of the spectrum) can be assumed in all the cases. Thus, the safety factor of buildings can be expressed as the ratio of spectral displacement capacity and demand: $S F=S_{d c} / S_{d d}$.

$T_{\text {eff }}>T_{C}$ is a robust assumption for buildings of at least 2 storeys designed according to EC8 spectra (types 1 and 2, for any soil type), see Gómez-Martínez (2015). It is based on the design elastic period suggested by EC8 as lower bound value for "modern" capacity-designed and DLS-designed frames (Crowley and Pinho, 2010), and on mean member stiffness degradation ratio from elastic to effective (0.20) proposed by Panagiotakos and Fardis (2001) as representative of the whole frame behaviour.

Spectral displacement capacity of the SDOF is obtained from top displacement capacity of the frame $\left(D_{u}\right)$ as in Eq. 1, being $\Gamma$ the first mode participation factor, and $\theta_{u, \min }$ the minimum ultimate chord rotation among those at (i) column bases, (ii) column tops at a height of $H_{\text {mec }}$ (both $\theta_{u c}$ ), and (iii) beam ends under $H_{\text {mec }}\left(\theta_{u b}\right)$ (Fardis, 2009).

$S_{d c}=\frac{D_{u}}{\Gamma} \approx \frac{H_{m e c} \cdot \theta_{u, \min }}{\Gamma}$

As shown in Fig. 8, a "rigid" mechanism of $n$ storeys is assumed, without any preyielding contribution neither of the (n-1) upper storeys nor of the intermediate column ends, and assuming similar evolution of chord rotations in all the member ends involved. The above assumptions are at the basis of other spectral approaches (Mazzolani and Piluso, 1997; Calvi, 1999; Decanini and Mollaioli, 2000; Cosenza et al., 2005; Iervolino et al, 2007; Borzi et al., 2008). 


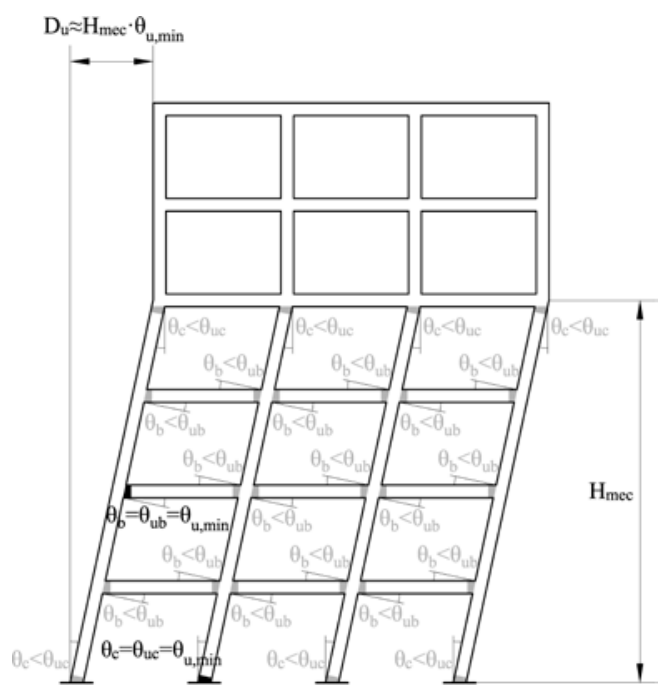

Fig. 8: Simplified estimation of the top displacement capacity of a frame

The displacement demand $\left(S_{d d}\right)$ can be obtained from the code-based elastic spectral acceleration demand ( $\left.S_{a e, d}\right)$, which is typically inversely proportional to the period for $T_{e f f}>T_{C}$ (see Eq. 2), being $f_{0}$ the maximum spectral amplification. Therefore, $S F$ of a building can be expressed as in Eq. 3, where the first term of the product is constant and independent from the structural system.

$$
\begin{aligned}
& S_{d d}=S_{a e, d} \cdot\left(\frac{T_{e f f}}{2 \pi}\right)^{2}=\left(f_{0} \cdot P G A_{d} \cdot \frac{T_{C}}{T_{e f f}}\right)\left(\frac{T_{e f f}{ }^{2}}{4 \pi^{2}}\right)=\frac{f_{0} \cdot P G A_{d} \cdot T_{C}}{4 \pi^{2}} \cdot T_{\text {eff }} \\
& S F=\frac{P G A_{c}}{P G A_{d}}=\frac{S_{d c}}{S_{d d}} \approx \frac{4 \pi^{2}}{f_{0} \cdot P G A_{d} \cdot T_{C}} \cdot \frac{H_{m e c} \cdot \theta_{u, \text { min }}}{\Gamma \cdot T_{\text {eff }}}
\end{aligned}
$$

Eq. 3 shows that influence of local ductility $\left(\mu_{\theta}=\theta_{u} / \theta_{y}\right)$ of beams on SF is not explicit. Moreover, it is also possible that there is not either implicit influence; in fact, $\theta_{u, \min }$ seldom refer to beams. If “empirical” approach EC8-3 is considered for $\theta_{u}$ of sections, more critical (i.e., lower) values are typically expected for columns with respect to beams because of: (i) presence of axial load; (ii) lower $L_{V} / h$ for medium-high span range (unless higher cantilever behaviour is shown); and (iii) slightly lower $(\omega \% / \omega)$ (assuming regular distribution of reinforcement bars in the perimeter of the column section and local detailing of reinforcement in beams). Thus, $\theta_{u}$ of beams may not be relevant in most cases for global capacity of moment resisting frames.

On the other hand, $\theta_{y}$ of beams does have influence in the value of $T_{\text {eff, }}$ but there is not a direct equivalence between effective stiffness of beam ends and that of the whole frame, which 
also depend on columns. Moreover, when DLS rules the design process, again $\theta_{y}$ of beams would not have any influence on $T_{\text {eff }}$ as lateral stiffness of the frame becomes a target and section of columns are designed accordingly. Thus, local ductility of columns may be more relevant on the global ductility than that of beams.

\subsection{Estimation of relative performances between WBF and DBF}

In this section, a rough prediction of the relative global capacities between WBF and DBF in most practical cases is carried out. All the simplifications are assumed in order to be conservative from the point of view of WBF, i.e. unfavourable for WBF with respect to DBF. The legitimacy of such simplified estimation is limited, because not only the assessment procedure but also the parameters derived from design are assumed "a priori".

Relative $S F$ between WBF and DBF ( $S F_{W / D}$, see Eq. 4) when designed to the same $P G A_{d}$ is developed from Eq. 3. Fig. 9 provides a graphical example, in the ADRS format, of condition leading to same performances for WBF and DBF: the increase of $T_{\text {eff }}$ is balanced by a similar increase of displacement capacity. Fig. 9 shows bilinear capacity curves, corresponding IN2 curves (Dolšek and Fajfar, 2004), common demand spectrum, and scaled capacity spectrum with their corresponding values of $P G A_{c}$ both for WBF and DBF.

$S F_{W / D}=\frac{H_{m e c, W / D} \cdot \theta_{u, \min , W / D}}{\Gamma_{W / D} \cdot T_{e f f, W / D}}$

Both structures are assumed to be designed adopting similar $q$, similar corrections due to second-order effects, similar $\rho_{\text {tot }}$ between corresponding columns of both types, and similar $(\omega / \omega)$ between corresponding beams. Also $\Gamma$ may be similar for WBF and DBF, according to several codes (e.g., ASCE/SEI 41-06).

Regarding $T_{\text {eff, }}$ WBF may show lower period elongation $\left(T_{\text {eff }} / T_{e l}\right)$ than DBF, if the experimental behaviour shown in LaFave and Wight (2001) for single connections (see section 3.3) is extrapolated to the whole frame. Thus, $T_{\text {eff, w/B }}$ can be estimated (Eq. 5) as the ratio between elastic periods $\left(T_{e l, W / D}\right)$ weighted by a factor $f_{K, \text { sec }}$, which is included in Eq. 5 after being switched from stiffness-based to period-based. However, the experimental-based value $f_{K, \text { sec }} \approx 1.48$ (LaFave and Wight, 2001) is considered just as an upper-bound level. So, aimed at conservativeness, all the following simplified development are carried out assuming $f_{K, \text { sec }}=1$.

$T_{e f f, W / D}=T_{e l, W / D} \cdot f_{K, \text { sec }}^{-0.5}$ 


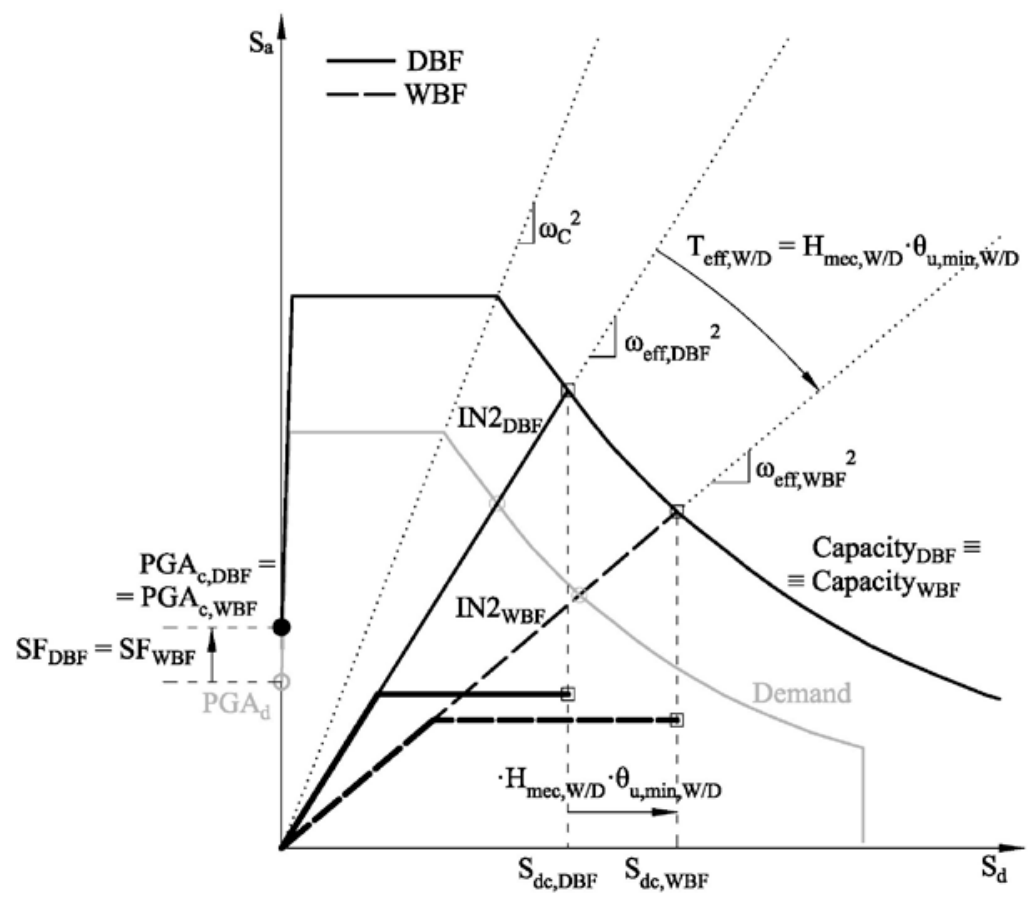

Fig. 9: ADRS condition for equal performances of WBF and DBF (increase of $T_{\text {eff }}$ balanced by the increase of $S_{d c}$ )

Given that $S F_{W / D}$ depends on the balance between $T_{e l, W / D}$ and $D_{u, W / D}$ (equal to $\left.H_{m e c, W / D} \cdot \theta_{u, m i n, W / D}\right)$, the comparison is organised in different scenarios depending on the magnitude of these factors. Regarding $T_{e l, W / D}$, two possible scenarios can be defined:

- $\quad$ Scenario I: similar $T_{e l}$ for both types $\left(T_{e l, W / D} \approx 1\right)$. It may correspond to a design situation in which the fulfilment of the IDR limitation becomes the most restrictive condition, thus leading to similar interstorey stiffnesses for WBF and DBF, and likely similar global stiffness and design period $T$, thanks to the use of larger column sections in WBF than in DBF (in order to balance the lower stiffness of WB). This scenario may be associated to structures designed in compliance with EC8 (Fardis, 2009).

- Scenario II: higher $T_{e l}$ for WBF $\left(T_{e l, W / D}>1\right)$. It may correspond to situations in which the design to DLS is not the critical condition. It can be a consequence of code prescriptions consideration of lower degradation of member stiffness (see section 3.3), higher maximum IDR (Table 1), higher stiffness of joint regions (Gómez-Martínez, 2015; Fardis, 2009) or larger effective width of upper slab (Table 1) — or conversely it can just reflect situations in which the relevance of DLS is low due to small seismic demand or due to 
higher relative importance of gravity loads -e.g. very high number of storeys (GómezMartínez et al., 2015c)—, regardless of the code adopted for design.

In general, the higher is the member overstrength ratio between columns and beams in a frame, the higher is $H_{\text {mec }}$. Considering that minimum $\rho_{\text {tot }}$ is required for columns, in general larger column sections causes higher overstrength. For both scenarios, columns of upper storeys may present larger sections for WBF rather than DBF because of beam effective width limitation in WB (see Table 1), especially when large $b_{w}$ are required for WB (i.e. high seismic demand or deflection limitation due to gravitational loads in large-span beams). Furthermore, for scenario I, larger column sections in the whole building are required for WBF rather than for DBF in order to provide similar stiffness (see section 3.3). Hence, $H_{\text {mec,W/D }}>1.0$ for scenario I and $H_{m e c, W / D} \geq 1.0$ for scenario II.

Regarding $\theta_{u, m i n, W / D}$, in each structural type the critical member can be a beam or a column. Therefore, four sub-scenarios of relative performances could be configured. WB show greater values of $\theta_{u}$ than DB (1.38 times could be a representative value according to section 3.2). In columns, local ductility increase with the section dimensions: substantial increase of secant stiffness is shown, while values of $\theta_{u}$ may not vary substantially (assuming fixed $L_{V}$ and axial loads, see Gómez-Martínez, 2015). Hence, $\theta_{u c, m i n, W / D}$ may be only proportional to $L_{V}{ }^{0.35}$. As cantilever behaviour may be higher for WBF than DBF, $L_{V, W / D} \geq 1.0$ and thus $\theta_{u c, m i n, W / D} \geq 1.0$. Hence, for WBF the probability for columns to be the first element to exhaust its rotation capacity may be higher than for DBF. The above consideration finds solid confirmation in other literature studies (e.g., Gómez-Martínez, 2015). The probability of occurrence of each situation depends of the ratio between $L_{V}$ of columns and beams: large-span buildings may show poorer performance for WBF than medium/short-span ones.

Nevertheless, it is not clear how smaller $S F_{W / D}$ should be in order to justify a reduction of $q$ for WBF. In fact, the implicit safety factor in $q$-based design is very high: quite large dispersion of results for SF can be observed between very similar structures, considering the very simplified nature of the $q$-based design and the non-negligible influence of personal choices of design (Mwafy and Elnashai, 2002).

Despite the limited scope of the simplified approach presented in this section, some relevant points can be remarked: 
- local ductility of beams may not be the most relevant parameter governing the relative performance of WBF and DBF;

- instead, global stiffness of the frame and overstrength of columns may rule $S F_{W / D}$, thus the more restrictive is the code regarding design to DLS, the more favourable is WBF performance respect to DBF one.

\section{CONCLUSIONS}

The reason why some Mediterranean codes do not consider reinforced concrete wide beam moment resisting frames (WBF) as high ductility systems is investigated. National codes of Spain, Italy, Greece and Turkey are compared with benchmark codes of Europe, USA, and New Zealand. Based on the traditional identification of flat-slab frames with WBF, also code limitations on flat slabs are examined in order to understand the analogy with some specific provisions on wide-beam frames. Experimental studies on wide beams are then reviewed, and strut-and-tie micro-models for connections are discussed.

From review of codes and experimental studies, it emerged that the only basis on which some codes, such as the Italian and the Spanish ones, prescribe a significant reduction of the behaviour factor for WBF (i.e., 33\% and 50\% respectively) is the poorer local ductility of wide beams respect to deep beams. Modern code provisions overcome other potential shortcomings of WBF, as stress transfer in connections or their higher deformability.

Thus, the capable local and global ductility of wide-beam frames (WBF) is investigated with respect to deep beam frames (DBF). Analytical results and a systematic comparison between wide and deep beams are provided. First, a detailed parametric analysis of local ductility of beams is carried out. Then, a spectral-based simplified approach is proposed for the comparison of global capacity of wide and deep beam frames.

Results show that the set of prescriptions given by each modern seismic code provides sufficient ductility to WBF designed in DCH. In fact, global ductility of WBF relies more on the lateral stiffness of the frames and on the overstrength of columns rather than on the local ductility of wide beams, systematically lower with respect to that of deep beams. Thus, the more a code provides restrictive provisions on damage limitation, the more any performance gap between WBF and DBF can be neglected. If damage limitation becomes the critical condition of design, 
likely similar stiffnesses are expected for both frames, while displacement capacities may be larger for WBF due to larger column overstrengths.

Hence, based on the analytical results and on the simplified spectral considerations provided, it could be stated that wide-beam frames can be designed as high ductility systems, and no reduction of $q$ is necessary for their design for codes in which damage limitation is likely to be the critical condition and specific provision for satisfactory performances of wide beam-column connections are provided.

\section{REFERENCES}

ACI (1989). Building Code Requirements for Reinforced Concrete (ACI 318-89). ACI Committee 318, American Concrete Institute, Farmington Hills, Michigan, USA.

ACI (2008). Building Code Requirements for Structural Concrete (ACI 318-08) and Commentary (31808). ACI Committee 318, American Concrete Institute, Farmington Hills, Michigan, USA

ACI-ASCE (1991). Recommendations for Design of Beam-Column Connections in Monolithic Reinforced Concrete Structures (ACI 352R-91). Joint ACI-ASCE Committee 352, American Concrete Institute, Farmington Hills, Michigan, USA.

ACI-ASCE (2002). Recommendations for Design of Beam-Column Connections in Monolithic Reinforced Concrete Structures (ACI 352R-02). Joint ACI-ASCE Committee 352, American Concrete Institute, Farmington Hills, Michigan, USA.

Arslan, M. H., Korkmaz, H. H. (2007). What is to be learned from damage and failure of reinforced concrete structures during recent earthquakes in Turkey? Engineering Failure Analysis, 14(1), 1-22.

ASCE (2007). Seismic Rehabilitation of Existing Buildings, ASCE/SEI 41-06. American Society of Civil Engineers, Reston, Virginia, USA

ASCE (2010). Minimum Design Loads for Building and Other Structures, ASCE/SEI 7-10. American Society of Civil Engineers, Reston, Virginia, USA.

Benavent-Climent, A. (2007). Seismic behavior of RC side beam-column connections under dynamic loading. Journal of Earthquake Engineering 11:493-511.

Benavent-Climent, A., Cahís, X., Zahran, R. (2009). Exterior wide beam-column connections in existing RC frames subjected to lateral earthquake loads. Engineering Structures 31:1414-1424.

Benavent-Climent, A., Cahís, X., Vico, J.M. (2010). Interior wide beam-column connections in existing RC frames subjected to lateral earthquake loading. Bulletin of Earthquake Engineering 8:401-420.

Benavent-Climent, A., Zahran, R. (2010). An energy-based procedure for the assessment of seismic capacity of existing frames: application to RC wide beam systems in Spain. Soil Dynamics and Earthquake Engineering 30:354-367

BHRC (2004). Iranian Code of Practice for Seismic Resistant Design of Buildings. Standard $N^{\circ} 2800,3^{\text {rd }}$ edn. Building and Housing Research Center, Tehran, Iran.

BSI (2004). Eurocode 2: Design of concrete structures: Part 1-1: General rules and rules for buildings. British Standards Institutions, London, UK. 
Borzi, B., Elnashai, A.S. (2000). Refined force reduction factors for seismic design. Engineering Structures 22:1244-1260.

Borzi, B., Pinho, R., Crowley, H. (2008). Simplified pushover-based vulnerability analysis for large-scale assessment of RC buildings. Engineering Structures 30:804-820.

Calvi, G.M. (1999). A displacement-based approach for vulnerability evaluation of classes of buildings. Journal of Earthquake Engineering 3(3):411-438.

CEN (2004). Eurocode 8: design of structures for earthquake resistance - Part 1: general rules, seismic actions and rules for buildings. European Standard EN 1998-1:2003 - Comité Européen de Normalisation, Brussels, Belgium.

CEN (2005). Eurocode 8: design of structures for earthquake resistance - Part 3: assessment and retrofitting of buildings. European Standard EN 1998-1:2005 - Comité Européen de Normalisation, Brussels, Belgium.

CDSC (1994). Seismic construction code, NCSR-94. Committee for the Development of Seismic Codes, Spanish Ministry of Construction, Madrid, Spain (in Spanish).

CDSC (2002). Seismic construction code, NCSE-02. Committee for the Development of Seismic Codes, Spanish Ministry of Construction, Madrid, Spain (in Spanish).

Cheung, P.C., Paulay, T., Park, R. (1991). Mechanisms of slab contributions in beam-column subassemblages. ACI special publication(123).

Cosenza, E., Manfredi, G., Polese, M., Verderame, G.M. (2005). A multilevel approach to the capacity assessment of existing RC buildings. Journal of Earthquake Engineering 9(1):1-22.

Crowley, H., Pinho, R. (2010). Revisiting Eurocode 8 formulae for periods of vibration and their employment in linear seismic analysis. Earthquake Engineering and Structural Dynamics 39:223-235.

CS.LL.PP (2009). Instructions for the application of the Technique Code for the Constructions. Official Gazette of the Italian Republic, 47 (in Italian).

Decanini, L.D., Mollaioli, F. (2000). Analisi di vulnerabilità sismica di edifici in cemento armato prenormativa - Comportamento sismico di edifici in cemento armato progettati per carichi verticali. E. Cosenza ed., CNR - Gruppo Nazionale per la Difesa dei Terremoti, Rome, Italy (in Italian).

De Luca F., Vamvatsikos D., Iervolino I. (2013) Near-optimal piecewise linear fits of static pushover capacity curves for equivalent SDOF analysis, Earthquake Engineering and Structural Dynamics, 42(4): 523-543.

De Luca, F., Verderame, G.M., Gómez-Martínez, F., Pérez-García, A. (2014). The structural role played by masonry infills on RC building performances after the 2011 Lorca, Spain, earthquake. Bulletin of Earthquake Engineering 12(5):1999-2026.

Domínguez, D., López-Almansa, F., Benavent-Climent, A. (2014). Comportamiento para el terremoto de Lorca de 11-05-2011, de edificios de vigas planas proyectados sin tener en cuenta la acción sísmica. Informes de la Construcción 66(533):e008 (in Spanish).

Domínguez, D., López-Almansa, F., Benavent-Climent, A. (2016). Would RC wide-beam buildings in Spain have survived Lorca earthquake (11-05-2011)? Engineering Structures 108:134-154

Dönmez, C. (2013). Seismic Performance of Wide-Beam Infill-Joist Block RC Frames in Turkey. Journal of Performance of Constructed Facilities, 29(1), 04014026.

Dolšek, M., Fajfar, P. (2004). IN2 - A simple alternative for IDA. Proceedings of the $13^{\text {th }}$ World conference on Earthquake Engineering. August 1-6, Vancouver, Canada. Paper 3353. 
Fadwa, I., Ali, T.A., Nazih, E., Sara, M. (2014). Reinforced concrete wide and conventional beam-column connections subjected to lateral load. Engineering Structures 76:34-48

Fardis, M.N. (2009). Seismic Design, Assessment and Retrofitting of Concrete Buildings. Ed. Springer, London, UK.

Gentry, T.R., Wight, J.K. (1992). Reinforced concrete wide beam-column connections under earthquaketype loading. Report $\mathrm{n}^{\circ}$ UMCEE 92-12. Department of Civil and Environmental Engineering, University of Michigan, Ann Arbor, Michigan, USA.

Gómez-Martínez, F. (2015). FAST simplified vulnerability approach for seismic assessment of infilled RC MRF buildings and its application to the 2011 Lorca (Spain) earthquake. PhD Thesis, Polytechnic University of Valencia, Spain.

Gómez Martínez, F., Pérez García, A., De Luca, F., Verderame, G.M. (2015a). Comportamiento de los edificios de HA con tabiquería durante el sismo de Lorca de 2011: aplicación del método FAST. Informes de la Construcción 67(537):e065 (in Spanish).

Gómez-Martínez, F., Pérez-García, A., Alonso Durá, A., Martínez Boquera, A., Verderame, G.M. (2015b). Eficacia de la norma NCSE-02 a la luz de los daños e intervenciones tras el sismo de Lorca de 2011. Proceedings of Congreso Internacional sobre Intervención en Obras Arquitectónicas tras Sismo: L’Aquila (2009), Lorca (2011) y Emilia Romagna (2012), may 13-14, Murcia, Spain (in Spanish).

Gómez-Martínez, F., Verderame, G.M., De Luca, F., Pérez-García, A., Alonso-Durá, A. (2015c). High ductility seismic performances of wide-beam RC frames. XVI Convegno ANIDIS. September 13-17, L’aquila, Italy.

Hawkins, N.M., Mitchell, D. (1979). Progressive collapse of flat plate structures. ACI Journal(7):775-808.

Iervolino, I., Manfredi, G., Polese, M., Verderame, G.M., Fabbrocino, G. (2007). Seismic risk of RC building classes. Engineering Structures 29(5):813-820.

Inel, M., Ozmen, H. B., Akyol, E. (2013). Observations on the building damages after 19 May 2011 Simav (Turkey) earthquake. Bulletin of Earthquake Engineering, 11(1), 255-283.

Kurose, Y., Guimaraes, G.N., Zuhua, L., Kreger, M.E., Jirsa, J.O. (1991). Evaluation of slab-beamcolumn connections subjected to bidirectional loading. ACI special publication(123).

LaFave, J.M., Wight, J.K. (1997). Behavior of reinforced exterior wide beam-column-slab connections subjected to lateral earthquake loading. Report $n^{0}$ UMCEE 97-01. Department of Civil and Environmental Engineering, University of Michigan, Ann Arbor, Michigan, USA.

LaFave, J.M., Wight, J.K. (1999). Reinforced concrete exterior wide beam-column-slab connections subjected to lateral earthquake loading. ACI Structural Journal 96(4):577-586.

LaFave, J.M., Wight, J.K. (2001). Reinforced concrete wide-beam construction vs. conventional construction: resistance to lateral earthquake loads. Earthquake Spectra 17(3):479-505.

López-Almansa, F., Domínguez, D., Benavent-Climent, A. (2013). Vulnerability analysis of RC buildings with wide beams located in moderate seismicity regions. Engineering Structures 46:687-702.

Li, B., Kulkarni, S.A. (2010). Seismic behavior of reinforced concrete exterior wide beam-column joints. Journal or Structural Engineering (ASCE) 136(1):26-36.

Masi, A., Santarsiero, G., Nigro, D. (2013a). Cyclic tests on external RC beam-column joints: role of seismic design level and axial load value on the ultimate capacity. Journal of Earthquake Engineering 17(1):110-136. 
Masi, A., Santarsiero, G., Mossucca, A., Nigro, D. (2013b). Seismic behaviour of RC beam-column subassemblages with flat beam. Proceedings of XV Convegno della Associazione Nazionale Italiana di Ingegneria Sismica, ANIDIS. Padova, Italy.

Mazzolani, F.M., Piluso, V. (1997). Plastic design of seismic resistant steel frames. Earthquake Engineering and Structural Dynamics 26:167-191.

MEPP (2000a). Greek Earthquake Resistant Design Code, EAK 2000. Ministry of Environment, Planning and Public Works, Athens, Greece.

MEPP (2000b). Greek Code for the Design and Construction of Concrete Works, EKOS 2000. Ministry of Environment, Planning and Public Works, Athens, Greece (in Greek).

Miranda, E., Bertero, V.V. (1994). Evaluation of strength reduction factors for earthquake-resistant design. Earthquake Spectra 10(2):357-379.

MPWS (2007). Specifications for buildings to be built in seismic areas. Turkish Standards Institution, Ministry of Public Works and Settlement, Ankara, Turkey (in Turkish).

Mwafy, A.M., Elnashai, A.S. (2002). Calibration of force reduction factors of RC buildings. Journal of Earthquake Engineering 6(2):239-273.

NZS (2004). Structural Design Actions. Part 5: Earthquake actions, NZS 1170.5. New Zealand Standards, Wellington, New Zealand.

NZS (2006). Concrete Structures Standard: Part 1 - The Design of Concrete Structures, NZS 3101 part 1. New Zealand Standards, Wellington, New Zealand.

Pan, A., Moehle, J.P. (1989). Lateral displacement ductility of reinforced concrete flat plates. ACI Structural Journal 86(3):250-258.

Panagiotakos, T.B., Fardis, M.N. (2001). Deformations of reinforced concrete members at yielding and ultimate. ACI Structural Journal 98(2):135-148 and Appendix 1 (69 pp.).

Paulay, T., Priestley, M.J.N. (1992). Seismic design of concrete and masonry structures. John Wiley and Sons, New York, USA.

Quintero-Febres, C.G., Wight, J.K. (1997). Investigation on the seismic behavior of RC interior wide beam-column connections. Report $\mathrm{n}^{\circ}$ UMCEE 97-15. Department of Civil and Environmental Engineering, University of Michigan, Ann Arbor, Michigan, USA.

Quintero-Febres, C.G., Wight, J.K. (2001). Experimental study of Reinforced concrete interior wide beam-column connections subjected to lateral loading. ACI Structural Journal 98(4):572-582.

Serna-Ros, P., Fernández-Prada, M.A., Miguel-Sosa, P., Debb, O.A.R. (2001). Influence of stirrup distribution and support width on the shear strength of reinforced concrete wide beams. Magazine of Concrete Research 54(00):1-11.

Siah, W.L., Stehle, J.S., Mendis, P., Goldsworthy, H. (2003). Interior wide beam connections subjected to lateral earthquake loading. Engineering Structures 25:281-291.

Shuraim, A.B. (2012). Transverse stirrup configurations in RC wide shallow beams supported on narrow columns. Journal of Structural Engineering 138(3):416-424.

Tore, E., Demiral, T. (2014). A parametric study of code-based performance limits for wide beams. eGFOS, 5(8), 1-11.

Vamvatsikos, D., Cornell, C.A. (2002). Incremental Dynamic Analysis. Earthquake Engineering and Structural Dynamics, 31:491-514. 
Vidic, T., Fajfar, P., Fischinger, M. (1994). Consistent inelastic design spectra: strength and displacement. Earthquake Engineering and Structural Dynamics 23:507-521.

Vielma, J.C., Barbat, A.H., Oller, S. (2010). Seismic safety of low ductility structures used in Spain. Bulletin of Earthquake Engineering 8:135-155. 